\title{
Plan de paz: transformar conflictos para buscar la paz
}

Puesto que no son pocos los desencuentros entre las partes del conflicto y los garantes, se propone la minimización de su participación en cuanto a la discusión de las pretensiones de las partes. Así, he optado por apoyar unas negociaciones que tengan como principio el diálogo directo (cara a cara) entre los implicados. ¿Por qué se propone esto? porque solo las partes conocen la realidad del surgimiento del conflicto, y solo ellas han sufrido durante décadas el desgarro socio-político de sus sociedades.

Se han edificado una serie de posibles escenarios de resolución del conflicto, al tiempo que se decidió construir un modelo, a largo plazo, en el que las partes negociarán de forma directa y con el acompañamiento de observadores de la ONU. Además se abre la posibilidad de la participación de garantes de la comunidad internacional (siendo esta propuesta decisión de las partes), los cuales no necesariamente tendrán que ver con la vida política, pues pueden ser personas ajenas a este aspecto.

Se construye un modelo que en todo caso propenda por la consecución de una paz negociada, basada en la situación real de la zona y que sea duradera y creíble en beneficio de ambas partes. De cualquier forma se aboga por la necesidad de la creación de un Estado para el pueblo palestino, al tiempo que se reconoce la imperante necesidad de que la consecución de la paz se ejecute bajo la garantía de una 
seguridad creíble y sólida para el Estado de Israel. Estos dos puntos son esenciales para que los dos pueblos vivan como vecinos pacíficos.

El modelo a largo plazo va en contraposición a aquellos planes de paz -que son la mayoría- que han sido diseñados teniendo como base una fecha de caducidad de las negociaciones. Mi crítica va dirigida a estos últimos, a los diferentes gobiernos estadounidenses que así los han diseñado, al Cuarteto para Oriente Próximo que también entró en la misma dinámica. Es de vital importancia generar unas negociaciones de paz sin presiones externas, sin fecha límite para su materialización; en cuyo caso la discusión de los puntos estructurales profundos debe ser la primera y no la última fase de las negociaciones, que es lo que ha venido ocurriendo desde el principio.

La solicitud de asistencia de observadores de la ONU responde al principio de neutralidad que estos -se supone- representan, pues es notorio que de parte de algunas agencias de este organismo existe una parcialización, por lo que también elevo una crítica al discurso que estigmatiza a las partes denominándolos como víctimas y victimarios. Esta crítica va encaminada a procurar no encasillar a las partes en un lado u otro, se propende en cambio por partir de un punto neutral donde ambas partes son iguales. Me acojo al marco conceptual que Jiménez Bautista denomina como paz neutra (Jiménez, 2009a y 2011), al ser esta una nueva forma de eliminar los extremos de las violencias culturales y simbólicas.

Para este modelo ambas partes son iguales, porque ambas han sufrido el rigor del conflicto. Las víctimas han sido de ambos lados y ambos han demostrado tener fortalezas en distintos aspectos, así como Israel tiene fortaleza militar para defender su seguridad, la AP tiene una inmensa influencia diplomática que ha logrado estigmatizar al Estado de Israel en sociedades occidentales. En ambos lados se libra una batalla desde distintos frentes. Los errores que desde 1948 se han sucedido no han sido pocos, aunque también en el modelo a largo plazo se reconocen las bondades de algunas propuestas. Algunas de dichas propuestas han sido materializadas con el consenso de las partes, otras serían muy útiles en las negociaciones de paz, pero por razones políticas y personalistas de las partes no se han discutido, aunque al ser aplicadas generarían un avance significativo al interior del conflicto. 
Bajo este modelo, la paz entre israelíes y palestinos no admite invenciones vagas que pretendan la figuración de garantes ni observadores, esas mismas que en el pasado han existido; por el contrario se necesitan puntos que pueden ser traídos hoy a la mesa de diálogos y en eso hay que reafirmarse. Este modelo rescata propuestas creíbles que en su momento no fueron materializadas, también rescata el acuerdo Gaza-Jericó, hoy vigente con la firma de las partes, así como, propuestas sobre indemnizaciones a los refugiados que fueron diseñadas por la Agencia de Naciones Unidas para los Refugiados Palestinos (UNRWA), el Organismo de Obras Públicas y Socorro (OOPS) y la Comisión Clapp en su momento.

La concreción de pretensiones creíbles que puedan ser realizables es la base del modelo a largo plazo. Este modelo critica de forma tajante el tratamiento del conflicto desde algunos países de Occidente, así como de las negociaciones desde la base de la emotividad como perspectiva de solución. En todo caso, este modelo parte de la igualdad de las partes y de la realidad sobre el terreno como bases fundamentales para la solución, de carácter regional, de algunos puntos estructurales profundos, pues terceros países de la zona están implicados en dicha solución, pero al mismo tiempo admite que la solución de este conflicto no resolverá otros en la región, porque no tienen la misma naturaleza.

Lo anterior hace referencia al punto de los asentamientos directamente. Este punto complementa el diseño de unas fronteras creíbles y sólidas, que no deben tener como base las anteriores a 1967, aunque de esa forma la AP reconozca tácitamente al Estado de Israel, sino la situación que las partes afrontan en la actualidad. Es decir, la vuelta a las fronteras de 1967, rechazada por una de las partes y defendida por la otra, encriptó el conflicto y congeló todo tipo de negociación desde hace décadas. Jerusalén en el modelo de acuerdo a largo plazo es el punto más sensible, pues en esa ciudad está presente la identidad de ambos pueblos, a lo que no están dispuestas a renunciar, como lo han demostrado en repetidas ocasiones. En consecuencia se sugiere el desarrollo de dos sistemas de administración posibles, sobre los cuales las partes pueden debatir la conveniencia de uno u otro, incluso desarrollar de mutuo acuerdo su propio modelo a partir de dichos sistemas. 
Tal vez todos estemos de acuerdo con que para lograr la paz se necesitan dos y que, si la decisión de conseguirla es sincera, las partes deben adquirir sin fisuras dos aspectos básicos: compromiso y confianza. De lo contrario, todo esfuerzo que se haga en pro de la paz será estéril. Las partes deben asumir que ambas se verán abocadas a ceder en sus pretensiones y que esto, sin duda, será doloroso para las dos sociedades; lo que no se puede pretender es que una sola de ellas ceda, que es el caso actual, en el que solo al Estado de Israel se le exige que ceda parte del territorio en disputa.

Por último, debo hacer hincapié en nuestra crítica a cómo manejó el presidente Obama su proceso de paz, ¿̇o debemos decir a ningún plan de paz del presidente Obama? Hoy el proceso se encuentra en una congelación de más de dos años, en los que no se han promovido conversaciones, salvo las convocadas la primera semana de enero de 2012 por el Rey de Jordania, tendientes a destrabar las negociaciones, después de un inicio fallido hace tres años, en donde las partes fueron presionadas por el presidente de los Estados Unidos para asistir a las mismas. El resultado es el que hoy conocemos, el conflicto sigue y las negociaciones permanecen congeladas. A esto se suma el hecho de que la participación del segundo secretario de Estado del presidente Obama, John Kerry, no ha sido la mejor.

Ya en el segundo periodo del presiente Obama, las fisuras entre este y el primer ministro israelí Benjamín Netanyahu han sido notorias y sin el menor interés por ocultarlo. Así, por ejemplo: la visita de Netanyahu al Congreso de los Estados Unidos, días previos a su reelección en 2015 como primer ministro; la intervención del presidente Obama en las elecciones israelíes de 2015, en contra del primer ministro Netanyahu, además del acuerdo con Irán y el grupo de los 5+1, dinamitaron cualquier posibilidad para que entre ambos se diera un acercamiento que pusiera en marcha un compromiso real de abrir nuevamente las conversaciones. De hecho, al final de su mandato, el presidente Obama abandonó totalmente la iniciativa y la cedió a Francia, que ha puesto sobre la mesa una propuesta que en principio consistió en amenazar al Estado de Israel con reconocer a los palestinos como Estado, si el primero no se sentaba en la mesa de negociaciones. Esta iniciativa fue promovida por el ex canciller francés, Laurent Fabius. 
Pero no solo el congelamiento en la relación personal entre ambos líderes tuvo lugar hasta hoy, también el gobierno de François Hollande asumió hace unos pocos meses un inusitado entusiasmo por el proceso de paz: el presidente encargó a su dimitido ministro, Laurent Fabius, hacer todos los esfuerzos para restaurar el proceso. Fabius asumió el encargo haciendo toda clase de pronunciamientos, entre ellos presionó con reconocer los territorios palestinos como Estado, si el gobierno israelí no aceptaba volver a la mesa de negociaciones. En este sentido, «el ministro francés aseguró que París tratará en las próximas semanas de convocar una cumbre internacional para renovar el proceso de paz entre palestinos e israelíes y aseguró que, de fracasar el proyecto, Francia reconocerá formalmente el estado de Palestina» (EFE, 2016).

\section{Resolución, gestión y transformación del conflicto}

La solución negociada hacia la paz entre israelíes y palestinos, desde sus inicios, ha dejado en el camino toda una maqueta de planes fallidos, bien sea por razones políticas de ambas partes, por falta de confianza, por oportunismo (mayormente de países europeos), o por la incapacidad de dar continuidad a tan solo uno de los diversos planes de paz que se han diseñado para la zona; en resumidas cuentas, todos los planes han sido destrozados por ambas partes. Tal vez uno de los que mayor credibilidad generó fue Oslo; sin embargo tanto israelíes como palestinos han dado al traste con dicho Plan. Realmente este se llevó a cabo, más para sembrar las bases de lo que sería el acuerdo de paz, que para conseguir la paz concretamente.

Quizá los acuerdos de paz de Oslo fueron, en su momento, los que mayor expectativa generaron. Antes de estos no se había llegado tan lejos en un diálogo directo entre las partes, pues este fue un compromiso asumido de forma bilateral, que se vio sólido y creíble. Generalmente cuando se habla de la resolución del conflicto y la búsqueda de la paz, sendos son los estudios y análisis que parten desde la perspectiva de Oslo. Sin embargo, los acuerdos de Oslo fueron poco a poco deshilachados por ambos actores del conflicto, si tenemos en cuenta que sus dos pilares básicos fueron: 1) libertad de movimiento de los individuos y 2) medidas de confianza y reconstrucción. 
En cuanto al primero, la construcción del muro de seguridad israelí tiró por tierra este principio; no obstante, adicional a esto, en 2005 Israel concreta la desconexión de Gaza, es decir, da y quita al mismo tiempo. Con respecto al segundo pilar, en ese momento era prácticamente imposible hablar de confianza cuando la II Intifada causó sendos atentados terroristas dentro de Israel. Podemos afirmar que la desconfianza y el miedo son concretamente los padres de la no solución del conflicto israelí-palestino. Esto sin descartar el creciente terrorismo de Hamas que día a día cobra más víctimas israelíes y que tiene que ver con la mutación de su terrorismo para sacar ventaja de él.

En la historia moderna no han sido pocas las veces que se ha escrito, analizado y debatido un posible plan de paz para este conflicto. La estadística de los personajes de alto nivel que han escrito y analizado este tema es extensa: Simón Peres, Edward Said, junto a sectores militares israelíes, universidades, políticos, estudiantes, diversos colectivos, entre otros, han investigado sobre el núcleo mismo del conflicto. El mundo ha aceptado la complejidad de este conflicto, así como de otros, pero si otros se han resuelto, aun con las dificultades propias de cada circunstancia, el conflicto israelí-palestino también se puede resolver, sobre todo si se reduce la intervención de terceros países, denominados El Cuarteto. La iniciativa europea ha sido, a través de la historia, dañina para la resolución de este conflicto y hoy lo es aún más. Los altos índices de antisemitismo creciente en Europa no pasan desapercibidos por la sociedad israelí, y sin duda la figura de Barack Obama hoy tampoco goza de mayor aceptación entre esta sociedad.

El mundo ha visto el final del conflicto entre comunismo y capitalismo -que creíamos eterno-, hemos visto acabar con el apartheid en Suráfrica, pero ¿por qué no hemos visto avances sólidos y contundentes en la búsqueda de la paz entre israelíes y palestinos? Hay un punto en común entre ambos actores, que hace que este conflicto, en lugar de transformarse y dar pasos hacia delante, continué suspendido en el tiempo. Están las razones geopolíticas políticas y de seguridad, por parte de Israel, y las territoriales y religiosas para los palestinos, pero ambos confluyen en un tema común, Jerusalén, ciudad con la que se identifican las dos civilizaciones. 


\section{Breve historia sobre los planes de paz}

Los diversos planes de paz que han pasado por el camino del conflicto israelí-palestino -desde las negociaciones entre las partes y el mediador (Los Estados Unidos), pasando por Camp David I, Sharm El Sheikh y sus posteriores fracasos-, han permitido que desde otros espacios civiles, sociales o académicos, este tema tenga una vigencia constante. Un estudio y su debate intrínseco casi de desgaste, tanto como el conflicto mismo, han generado que el análisis de la búsqueda de la paz sea constante; de hecho se puede afirmar que se convierte en un desafío para los investigadores de la paz, quienes deben asumirlo con la misma entereza y continuar con su análisis.

Durante el periodo del presidente Obama, las negociaciones han sido un total fracaso, entre otros motivos porque prácticamente se obligó a las partes a iniciar los diálogos, primero con Hillary Clinton como secretaria de Estado, situación que no cambió cuando asumió John Kerry. Si no había compromiso para iniciarlos, es evidente que tampoco lo había para el consenso. Dos razones claras para dicho fracaso fueron:

a. Ninguna de las partes, individual o conjuntamente, se fijó metas claras o intereses durante la negociación, en muchos niveles, por lo que las negociaciones en su mayoría fueron a escondidas y el objetivo del programa estaba en contradicción absoluta con los propósitos declarados del proceso político.

b. Ambas partes mantuvieron negociaciones sin tomar una decisión estratégica, en términos de la decisión histórica, en cuanto a la resolución del conflicto, mientras que aceptaron llegar a un acuerdo con los compromisos que se requieren de cada parte (Peres, 2010).

Visto lo anterior, es claro que no era posible llegar a un acuerdo de paz en el 2009 y tampoco hoy en 2016. Las dos razones anteriores justifican mi argumentación, pues no es posible presionar a las partes para que se reúnan, y ese fue y seguirá siendo el error cometido. La búsqueda de la paz no necesita presiones, pues para ello es necesaria la voluntad. Allí llegaron los líderes israelí y palestino de forma presionada, por lo que el resultado es el que conocemos hoy. 
$\mathrm{Al}$ interior del conflicto es necesario anteponer premisas sobre las cuales se negocia la paz, no siendo estas exclusivas de una u otra parte, por el contrario, son vinculantes a ambos actores. Con esto se logra construir la paz desde bases sólidas y creíbles que impidan la generación de una paz fallida o de poca duración, que cause nuevamente inestabilidad en la zona.

a. Compromiso y la participación (en términos de una decisión estratégica) en nombre de cada parte para llegar a un acuerdo global y permanente.

b. Disposición en nombre de las partes a participar en un proceso continúo y serio de diálogo a través de negociaciones directas. (Peres, 2010).

Si no se parte del compromiso sincero por conseguir la paz ¿cómo se puede conseguir esta? En líneas anteriores he defendido los diálogos directos, cara a cara entre las partes, a fin de desmantelar todos y cada uno de aquellos aspectos que históricamente han trabado el conflicto, por ejemplo, la carga cultural e histórica de ambas partes sobre la tierra en disputa. A esto la UNESCO agrega una carga violenta, toda vez que esta agencia de Naciones Unidas insiste en re-escribir la historia a través de polémicas decisiones sobre las zonas históricas de la ciudad de Jerusalén. La más reciente resolución tuvo lugar el 17 de abril de 2016, en la que el organismo presidido por la búlgara, Irina Bokova, niega todo vínculo entre los judíos y el Monte del Templo donde se ubica el Muro de las Lamentaciones.

El ex ministro de Finanzas y presidente del partido, Yesh Atid, diputado Yair Lapid también escribió una carta punzante a la UNESCO, advirtiendo a la presidenta de la organización, Irina Bokova, que la decisión de tratar de divorciar a los judíos de los dos lugares sagrados dará lugar a un derramamiento de sangre. (Aurora, 2016).

La búsqueda de la paz, a lo largo de los años, ha dado lugar a múltiples escenarios: desde conferencias internacionales con diferentes 
países involucrados, hasta las decisiones unilaterales de las partes, como la desconexión de Gaza, y, el más reciente, la voluntad de involucrar a todo el globo en la solución del conflicto israelí-palestino, como lo hace hoy la AP con su petición de reconocimiento de un Estado Palestino en la ONU. Lo anterior confirma que el conflicto no ha dejado de permanecer dentro de un espacio de constante mutación, en el que se pueden dar nuevos escenarios desde la actuación de ambas o una sola de las partes, lo que quiere decir que no es posible cerrar ninguna posibilidad de transformación de este conflicto.

La transformación de este conflicto ha sido constante, por ello aquí hablamos de mutación. No obstante, queda claro que estas transformaciones o mutaciones no han sido a favor de la búsqueda de la paz, pues no hemos observado ningún avance ni antes ni ahora. En nuestra opinión, la paz se inclina por la aplicación del primer modelo de la siguiente figura, es decir, un proceso de paz con base en unas negociaciones sobre un acuerdo a largo plazo (figura 2); sin embargo, se diseñó un modelo de escenario que denominaré global, pues admite diferentes escenarios con los que nos hemos encontrado en la historia del conflicto, aunque no por ello están exentos de ser aplicados dentro de un marco de confianza y compromiso de las partes.

Se debe asegurar que las partes permanecerán en la mesa de diálogo y negociación, sin prejuicio de los actos externos que durante el proceso de paz se puedan presentar, pero propendiendo por un compromiso absoluto por parte de la AP de repudiar los actos terroristas provenientes desde sus territorios. A continuación se desarrollará un modelo propio de búsqueda de la paz entre israelíes y palestinos, libre de fecha de caducidad; apostando por unas negociaciones a largo plazo y sin presiones externas, que concluyan con un diálogo directo que propicie la consolidación de una paz duradera para ambos pueblos, que pueden ir comprometiendo logros graduales o por etapas. 
Figura 2. Sobre distintos acuerdos

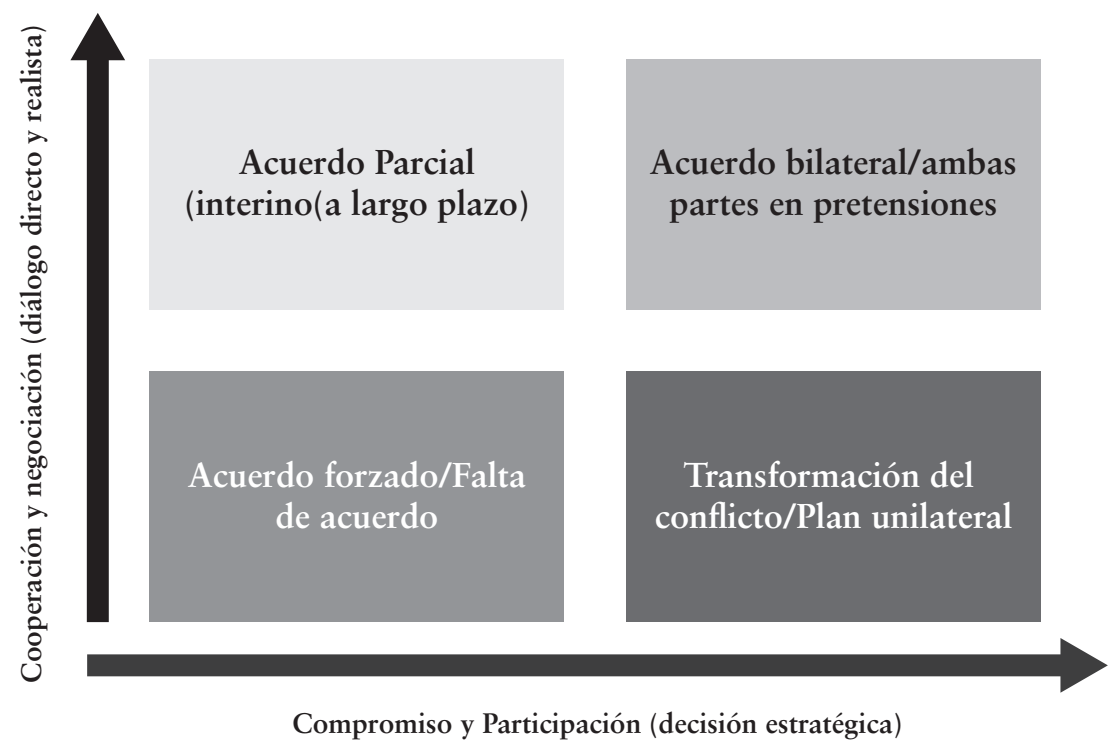

Fuente: Centro Peres para la Paz (s.f.).

\section{Acuerdo parcial, interino a largo plazo}

Para lograr este acuerdo parcial interino a largo plazo es necesario llevar a cabo una primera medida: no imponer límites (fecha final) a las negociaciones de paz. Siempre he defendido esta liberación de los diálogos como una necesidad expresa para conseguir un elemento clave del diálogo, la confianza. Esta debe ser conseguida a través de un esfuerzo tanto de israelíes como de palestinos, no es un asunto exclusivo de uno u otro, es una necesidad de ambos, si se quiere avanzar es este proceso. Actualmente, la situación en que se encuentra el conflicto, prácticamente congelado, corresponde a uno de los episodios más graves de la negociación; aunque se pensó que el presidente Obama, Premio Nobel de la Paz, llegaría con una solución, esta nunca vio la luz.

La falta de confianza ha minado el camino del diálogo. Las partes están alejadas y enrocadas en sus posiciones, y quien representa la mediación ha sido incapaz de contener la explosiva destrucción de 
la negociación de paz. Los temas materiales, que se deben abordar y que son las pretensiones que tienen cada una de las partes, tales como Jerusalén, el reconocimiento de un Estado Palestino, al tiempo que el reconocimiento de Israel como Estado judío, entre otros, deben ser acompañados de un trabajo de reconciliación, no entre líderes, sino entre pueblos, entre la sociedad civil o el ciudadano del común que nunca ha participado de las negociaciones de paz, solo del conflicto.

En mi opinión, los diálogos de paz deben ser llevados por las partes a lo terrenal, es decir, deben ser entendidos en su intríngulis por los habitantes de cada lado del conflicto. Este trabajo puede ser realizado por diferentes ONG neutrales, que garanticen la centralidad de su trabajo, que éstas abandonen su discurso de buenos y malos, que tanto daño ha causado a la sociedad civil de ambos lados del conflicto. Sin lugar a dudas, ni las ONG europeas ni los medios de comunicación de ese continente han aportado nada a la reconciliación, muy por el contrario, un penoso sentimiento anti-israelí emana cada día más fuerte.

Las negociaciones de paz a largo plazo, tendentes a la reconciliación, desde ningún punto de vista deben llevar la carga de la caducidad que hasta ahora todas han llevado, incluso esta última que ha sido encargada por las partes al Cuarteto para Oriente Medio (ONU, EE.UU. UE. y Rusia). Además, la confianza entre las partes deberá dar como resultado la respuesta a interrogantes como ¿a qué clase de acuerdo quieren llegar, interino o a largo plazo? Creo que, desde su aplicación, los dos tipos de acuerdos son aceptables, si lo que se quiere es una paz duradera y creíble.

En párrafos anteriores se ha hecho referencia a la carga cultural como base estructural de este conflicto, y en ello he de ratificarme, por lo que es necesario que el modelo de diálogo, elegido por las partes para seguir las negociaciones de paz, dé como resultado la aceptación del discurso cultural de israelíes y palestinos. Uno de los errores macro que han cometido las partes y el mediador es iniciar los diálogos desde arriba. Así, pretender solucionar el estatus de Jerusalén con un tiempo de caducidad inmerso en las negociaciones es imposible. Se ha iniciado desde arriba, desde lo más complejo para ambos, y se han abandonado temas sensibles como el agua, la movilidad de los ciudadanos de cada 
lado del conflicto, la salud, la educación, la seguridad; temas que no son de ninguna manera ajenos a la necesidad de paz.

Cada una de las partes debe tener derechos, no materiales, sino intangibles, que garanticen la vida de los ciudadanos comunes, tales como el derecho a la integridad física, moral y social, a la integración pacífica y a no tener miedo. Todos estos derechos, así como los anteriormente mencionados, deben hacer parte de un espacio temporal, durante el cual se suspenda todo tipo de ataque del lado palestino, lo cual debe garantizar como reciprocidad la no respuesta del lado israelí. Al mismo tiempo las partes tienen deberes, el más importante, según mi criterio, ha de provenir de la AP y consistente en un rechazo absoluto a los atentados terroristas cometidos por el Hamas. Frente a este aspecto el presidente Abbas no ha colaborado con la consecución de la paz.

A partir de lo anterior se puede construir un acuerdo interino o a largo plazo, en el cual se experimente con un modelo nuevo que construya la paz como se construye un edificio, desde abajo, con sólidas estructuras, creíbles para las partes y la comunidad internacional. En especial es importante demostrar que todo lo hecho anteriormente no solo representó un equívoco y una mal gestión, sino que también limitó a las partes y al mediador; por no mencionar el hecho de que fue un proceso muy alejado del ciudadano del común, que es en últimas por quien los actores dicen estar inmersos en el conflicto. A largo plazo, este tipo de acuerdo se establecen cuando los objetivos de la negociación son múltiples y muy complejos, en cuyo caso ninguna de las pretensiones ha sido resuelta todavía y no está previsto en el futuro inmediato resolverlas. Según Peres, «parcial / acuerdo provisional a largo plazo, expresa el reconocimiento de que el conflicto sólo puede resolverse a través de un acuerdo de paz o un acuerdo global, aún las condiciones para un acuerdo no están maduras todavía» (Peres, 2010).

En este sentido, las partes deben superar la desconfianza mutua, aun cuando es entendible hay razones suficientes para que esta exista, dado que cada una de las partes ha ignorado especificaciones hechas en negociaciones de paz anteriores. De este conflicto, se puede estar aportando un método que se plasme en un orden en el tiempo y el espacio para la discusión de las pretensiones estructurales profundas de las partes. 
La dialéctica de que una decisión favorece, de forma unilateral, a una parte u otra debe ser expulsada de las negociaciones de paz. Hasta ahora, ninguna de las partes se ha comprometido con ninguno de los puntos en discusión, más allá de la desconexión de Gaza por parte del entonces primer ministro, Ariel Sharon. Salvo este hecho, no ha habido más esfuerzos en el tema de los asentamientos, por lo que la AP tomó la decisión unilateral de llevar el conflicto a la ONU, con el fin de poder involucrar a todo el mundo. Hemos observado durante décadas que los puntos estructurales profundos son los mismos, estos no cambian:

- El estatus de Jerusalén

- Retorno de los refugiados

- Los asentamientos

- Fronteras de 1967

- Habría que agregar, la desmovilización de Hamas y un compromiso por la paz, que le permita ser excluido de la lista de grupos terroristas por Estados Unidos y la Unión Europea y, por ende, participar en los diálogos de paz. Aunque ante esto el gobierno de Israel es renuente.

La complejidad que subyace en estos puntos, no es una cuestión que se deba tratar en un corto plazo, pues de la solución de ellos depende en gran medida la paz en la zona. Por esta razón este modelo consiste en un cambio en el ritmo de las negociaciones, en dar una oportunidad a la confianza sobre la base del compromiso de ambas partes de llegar a acuerdos que deben ser respetados por quienes los suscriban, es decir, los mismos protagonistas del conflicto.

\section{El discurso}

Este es otro aspecto que necesariamente debe ser renovado y transformado, pues el discurso entre las partes será el que va a conseguir que las negociaciones estén exentas de cualquier insinuación negativa contra la otra parte. Este punto es, tal vez, uno de los que más necesite un trabajo por parte de las ONG, pues tanto adentro (en la zona) como en el exterior, muchas de estas organizaciones han caído en el discurso 
divisorio de víctimas y victimarios, creando un estado de desconfianza prácticamente global sobre lo que allí ocurre. La estigmatización del Estado de Israel debe desaparecer de los discursos de estas organizaciones. Es indiscutible que existe un discurso anti-israelí por parte de las ONG dentro y fuera de Israel.

Bajo este panorama, intentar aislar a Israel no es positivo para la solución del conflicto, ya que esto empeora la situación y congela las negociaciones. La constante de clasificar a unos como buenos y a otros como malos impide la solución pacífica, incluso muchas de estas organizaciones han desviado su camino, pues ser pacifista no es castigar al otro, no es discriminar dentro del conflicto, es debatir, unir y resolver conflictos, pero sin violencia, no de forma forzada como lo han venido haciendo muchas.

En un conflicto intercultural, como lo es el palestino-israelí, no favorece a ninguna de las partes que organizaciones externas realicen discriminaciones tendentes a evocar condenas internacionales por parte de otras organizaciones y mucho menos de otros Estados. La neutralidad es un derecho y una exigencia que la parte afectada puede invocar para destrabar las negociaciones de paz.

\section{Levantamiento de sanciones económicas}

De igual forma, situaciones como el boicot a los productos o personas israelíes en territorio europeo debe ser objeto de estudio en el escenario de negociación que aquí se propone. De nada han servido hasta hoy los llamados de políticos e intelectuales europeos a boicotear productos israelíes, máxime si estos generalmente proceden del trabajo de los kibutz que han sido históricamente zonas de paz. Debe ser contundente el rechazo, por parte de los gobiernos occidentales comprometidos con el proceso, a la organización Boicot, Sanción y Desinversión (BDS, por sus siglas en ingles) que se extiende con un discurso anti-israelí, tildado por algunos como antisemita.

El levantamiento del boicot no debe ser el resultado de la negociación, debe ser un incentivo para la misma. Europa se ha apropiado de un discurso que, desde la visión de una de las partes, va en clara 
intención en contra de ella; lo contrario ocurre con los Estados Unidos, quien, pese a las críticas sobre su mediación dentro del conflicto, ha conseguido la credibilidad de ambas partes, quizá porque ha sabido garantizar esa neutralidad.

El informe sobre Derechos Humanos del Departamento de Estado en 2016 constata este constante sentimiento de antisemitismo:

"El Observatorio sobre Antisemitismo en España informa de que los prejuicios sólidamente arraigados continúan” - describe el informe, reportando 42 "eventos antisemitas" en 2014 (ninguno de ellos violento) y seis menciones antisemitas en el discurso público, entre las que citan el tuit de Zapata [...] Además de los casos de Zapata y Matisyahu, el Departamento de Estado referencia el arresto por parte de la Guardia Civil de un grupo neonazi que realizó las pintadas “Adolf Hitler tenía razón”, o la denuncia contra hinchas de baloncesto por 18.000 presuntos tuits ofensivos tras un partido entre el Real Madrid y el Maccabi. (Fava, 2016).

Si Europa no coopera en cuanto a la libre circulación y expresión de personas israelíes en sus territorios y sus instituciones, ¿cómo podemos escuchar para luego debatir la posición de una de las partes en el conflicto? No es por lo tanto una posición enmarcada como pacífi$\mathrm{ca}$, dado que culpar a Israel de todo cuanto acontece en la zona no ha solucionado aún el conflicto.

La desconfianza de Israel hacia la intervención de Europa en la solución del conflicto viene acompañada de la hostilidad que algunos países han mostrado en su posición hacia el conflicto. En este sentido, acusar y condenar a Israel no resuelve nada, ellos, los israelíes, también necesitan la confianza de Europa, así como un acompañamiento despojado de prejuicios hacia su Estado, de otra forma Israel insistirá en relativizar la intervención europea en la solución del conflicto. Mis críticas van encaminadas a expresar toda necesidad de que el conflicto sea liberado de esas manifestaciones que, desde afuera, tienen gran culpa en el enquistamiento del mismo; una propuesta real, de diálogo directo, como la que esta investigación propone, debe ser cuidadosamente 
diseñada para que los factores externos no perjudiquen el desarrollo de este modelo de negociación.

El acuerdo interino a largo plazo es el mejor escenario para implementar y desarrollar en la zona, por lo que el diseño de un principio de acuerdo sobre puntos básicos (no estructurales) puede ser la fuente de nuevos acuerdos posteriores, siempre y cuando se tome en cuenta el resultado de lo que ocurra dentro de ese periodo de interinidad a largo plazo. Este periodo de interinidad debe incluso ir acompañado de unos observadores de Naciones Unidas que certifiquen la no violación del compromiso de las partes en su participación dentro del mismo, estos veedores deben trabajar bajo el principio de neutralidad dentro del acuerdo. Estos observadores neutrales, como es lógico, deberán permanecer en la zona mientras el acuerdo esté en funciones.

El acuerdo a interino a largo plazo debe, necesariamente, otorgar un espacio importante para que la población civil de ambos lados participe del desarrollo del mismo, por ejemplo, en las discusiones temáticas que aluden a la solución del conflicto ninguna idea debe ser despreciada. Se trata de construir paz a través de la transformación del conflicto y en esto la participación de la población civil puede ser el punto que equilibre las negociaciones de paz.

Es de especial relevancia que este acuerdo interino esté revestido de una especie de «blindaje» de seguridad y neutralidad, ambos temas en manos de la ONU. La presencia de los observadores de la ONU pondrá fin a la práctica bélica de acción-reacción entre las partes.

Otro aspecto especialmente importante es la suspensión de la práctica de acción-reacción, debe ser el resultado de un compromiso anterior a todo comienzo del acuerdo interino, de tal forma que se garantice la integridad física de los ciudadanos de ambos lados, así como de los observadores del proceso. Se busca con el acuerdo de interinidad una situación de no violencia que reduzca la tensión entre ambos pueblos, que dé como resultado una situación de confianza y sobre todo que se desarrolle desde la base del compromiso entre las partes de no suspenderlo a la primera situación que interprete como adversa. 
Figura 3. Esquema de diálogo

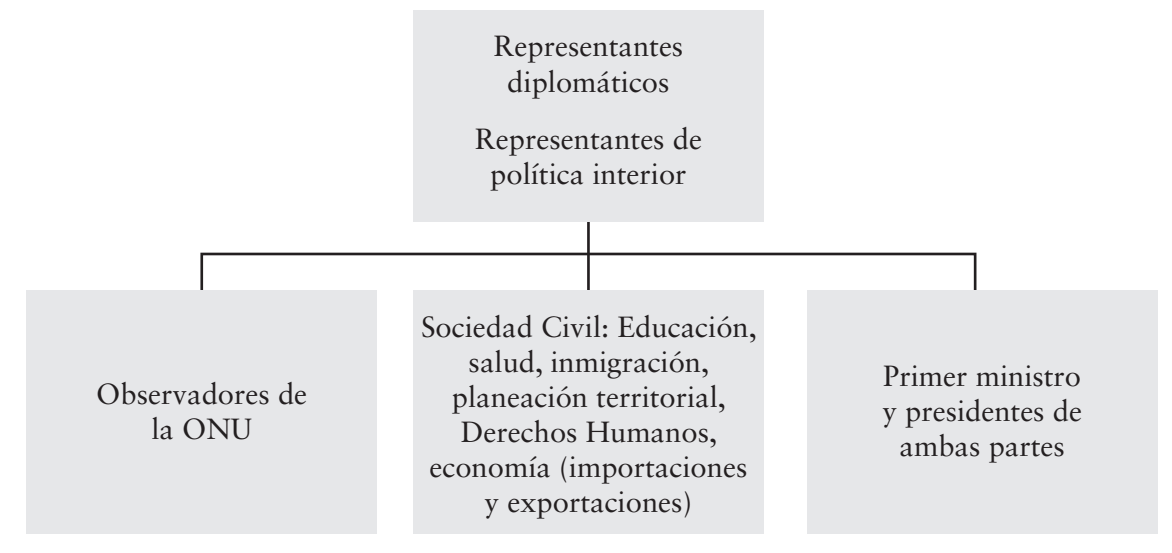

Fuente: elaboración propia

Dentro de este modelo, toda acción-reacción debe ser suspendida en busca del cese de las hostilidades y de la violencia directa, para cuyos efectos el espacio de interinidad debe ser un espacio de construcción de paz. Para suspender la acción-reacción se necesita involucrar a Hamas, que es el actor palestino violento discordante entre el lado de Gaza e Israel. "Manejo de conflictos conjunto con el consentimiento formal -de mutuo acuerdo entre las partes para establecer un período de calma en la zona, como el estado de Tahadyia con Hamas» (Peres, 2010).

Siendo un subactor del conflicto, Hamas debe estar involucrado dentro del acuerdo de interinidad e Israel deberá ceder ante la negativa de tratar con Hamas por su condición de grupo terrorista declarado por los Estados Unidos y Europa. Recordemos que, en el pasado, Israel ha negociado en sendas ocasiones con Hamas a través de intermediarios como el gobierno de Egipto, para el intercambio de secuestrados israelíes por presos palestinos, caso Guilad Schalid.

\section{El tercero neutral}

El modelo interino a largo plazo aboga por los observadores de la $\mathrm{Na}$ ciones Unidas como garantes del principio de neutralidad dentro del acuerdo de interinidad, por lo que su trabajo irá más allá de la observación, e involucra la participación activa para lograr destrabar los 
pequeños conflictos inter-partes que se puedan presentar; específicamente, nos referimos a aquellos que tienen que ver con la convivencia durante este lapso.

Si se busca la paz entre palestinos e israelíes es necesario, como lo ha mencionado el gobierno de Israel en sendas ocasiones, hacer sacrificios dolorosos. Sin embargo, en este acuerdo interino a largo plazo las partes se sentarán en la mesa en condición de igualdad; y en tal sentido es importarte aceptarse que sobre el terreno la premisa de tierra por paz, al menos para este momento, no será posible, pues no otorga garantías justas para una solución de satisfacción de las partes en igualdad de condiciones. Además, esta premisa fracasó y la muestra clara está en la desconexión de Gaza.

A pesar de lo anterior, una forma para que esta premisa pudiera funcionar sería que una de las partes cediera parte de la tierra que pretende (palestinos) y que al mismo tiempo la otra parte ceda una porción de tierra de la que actualmente está en su poder (israelíes). Para esto no es necesario acudir a viejos mapas de 1949 o 1967 con el fin de delimitar un futuro Estado palestino y un Estado israelí, pues es precisamente eso lo que hecho que el conflicto continúe. En cambio, es necesario generar un debate interpartes, además de un nuevo mapa, sobre la base de las circunstancias en las que se encuentre la situación al momento de desarrollar este modelo. Esto significa que se debe recurrir a la creatividad que tenga como base la realidad, en especial, si el objetivo es la construcción de paz. No hay razón para permanecer anclados en la inflexión metodológica en que permanecen las partes hoy en cuanto a la negación de las pretensiones del otro. Estas pretensiones existen, y por el hecho de ser reales es lo que emplaza a las partes a negociar sobre el realismo actual de la situación.

Despojadas de todo prejuicio anterior, las partes desarrollarán las negociaciones a favor de su situación interior y de cara al exterior, pero, insisto, es necesario disminuir la intervención europea y estadounidense, salvo que sea mediante el estatus de observador de la Naciones Unidas. El realismo y el diálogo directo deben llevar a las partes a asumir compromisos creativos, sólidos y creíbles, de cara al futuro de cada pueblo. 


\section{Puntos estructurales profundos}

Son los que constituyen el núcleo profundo del conflicto, los que tienen que ver con la identificación de las partes con la tierra y de ésta con la cultura de ambos lados del conflicto. Hablamos de Jerusalén, las fronteras de 1967, el retorno de los refugiados, los asentamientos, el reconocimiento del derecho de autodeterminación de los dos pueblos, la desmovilización de Hamas y su compromiso sólido con la paz, consistente en abandonar sus prácticas terroristas.

Estos puntos profundos estructurales deberán empezar a ser negociados dentro del espacio de tiempo contemplado en el modelo interino a largo plazo. Empero, no es posible afirmar en cuánto tiempo pueden finalizar las negociaciones sobre puntos primarios ni cuándo empezar las mismas, pues no se reconoce la caducidad dentro del conflicto. Solo los adelantos en las primeras negociaciones de cuestiones primarias determinarán la conveniencia o no del cuerdo. Las negociaciones sobre estos puntos deberán ser tratadas cara a cara entre los gobiernos, con la participación de la sociedad civil que es, en últimas, quien padece las consecuencias del conflicto que tiene causas estructurales culturales. Tal y como afirma Blumenthal, este «es un conflicto de mentalidades en el cual las partes hablan idiomas culturales diferentes, siendo la base de desentendidos que a veces ni las mejores traducciones logran superar. Es un conflicto entre religiosos y laicos, entre quienes santifican la tierra sobre la vida» (Blumenthal, 2010).

Estos puntos profundos, que en mi opinión son la base del conflicto, tienen su origen en la denominada cultura profunda, que es representativa del creer colectivo de un pueblo por su historia y su origen. Son ambas partes del conflicto quienes, con base en esa posesión de una cultura profunda, se han enraizado en un conflicto de desgaste sobre la tierra. Seis décadas de conflicto nos dan una idea global y compleja de los pasos que «no» se deben dar dentro de las negociaciones referentes a los puntos profundos, por cuanto pretender hacer señalamientos con respecto a pertenencias y no pertenencias absolutas sobre el territorio no será recomendable.

La negociación sobre estos puntos estructurales profundos no debe apartarse de la realidad actual. Existen miedos existenciales en 
ambos lados del conflicto -diría que incluso más del lado israelí que del palestino-, por lo que necesariamente este aspecto debe ser tenido en cuenta. Si bien se trata durante este periodo, en el mejor de los casos, de transformar el conflicto para buscar la paz, no es posible ignorar la realidad existente, esa es una de las premisas defendidas en esta investigación.

\section{Estatus de Jerusalén}

Desde el inicio, el tema de la ciudad ha determinado todo el espacio del conflicto, por lo que es la causa principal de que hasta hoy no se haya concluido ninguno de los sendos planes de paz propuestos. Concretamente se habla de tres kilómetros de tierra que albergan los lugares santos de las tres religiones del libro, en tal sentido, la ciudad ha sido y continúa siendo objeto de coexistencia de cultura, seguridad y estrategia para ambos actores del conflicto.

Con lo dicho hasta el momento podríamos decir -y no es exageración- que Jerusalén es, sin duda, la ciudad hoy existente con más contenido religioso; cuando hablamos de algo sacro, sea para judíos, sea para cristianos o para musulmanes. Sin embargo, esto no es todo pues además se trata de una ciudad con una historia turbulenta, quizá también como ninguna, a pesar del significado "ciudad de paz" con que quiere interpretarse el nombre Salem, con el cual se ha denominado por primera vez en la Biblia. Así cuando pensamos en Jerusalén pensamos también en "conflicto". (Bandak, 2010).

La importancia cultural de Jerusalén condiciona toda posible solución al conflicto entre israelíes y palestinos, de hecho es el origen del mismo; a lo cual se suma el hecho de que la imposibilidad de dividirla ha ocasionado la traba del conflicto. Ambos actores la proclaman como su capital, bien sea por historia, por cultura o por identidad (aunque he de decir que nunca se ha conocido la ciudad de Jerusalén como capital de otro país que no sea Israel). Por tal razón, la pregunta obligatoria es 
¿qué hacer con Jerusalén? Hasta ahora las partes, al proclamarla cada una como la capital de su Estado, dan por hecho que el plan de elevarla a un estatus internacional no está contemplado por ninguna de las dos. Aunque realmente el gobierno de la AP tiene su sede en Ramallah. El conflicto israelí-palestino es la materialización del choque de civilizaciones como ningún otro de los citados, incluso por el propio Huntington, como el de los Balcanes o entre Pakistán y la India. Este conflicto carece de ideología, tampoco es un conflicto entre estados-nación, su centro es la tierra que reclaman dos civilizaciones, el Islam y el Judaísmo. Incluso, podría ir más allá, según todo lo que rodea a nivel global este conflicto, para hablar de un conflicto del Occidente judeocristiano (representado en Israel) versus el Islam (representado por los palestinos), en el que de forma indirecta intervienen de cada civilización otros países a favor de ambas partes.

En el plano local, las líneas divisorias más violentas son las que separan el Islam de sus vecinos ortodoxos, hinduistas, africanos y cristiano-occidentales. En el plano universal, la división dominante es entre "Occidente y el resto del mundo", y los conflictos más intensos tienen lugar entre sociedades musulmanas y asiáticas, por una parte, y Occidente, por otra. (Huntington, 1997).

El choque de civilizaciones en este conflicto es algo que está ahí, que es real-aunque Occidente se niegue a aceptarlo- pero que ninguno de los actores o garantes ha reconocido. La historia del conflicto aboga necesariamente por un plan de diálogo directo y realista, como lo muestra el gráfico; por lo tanto, todo punto en discusión debe ser debatido sobre la base de la realidad actual, ya que esta determina las condiciones del conflicto. Sería erróneo pretender resolver dicho conflicto sobre situaciones pasadas o, en el peor de los casos, sobre situaciones que pretendan privilegiar a uno para aplastar al otro, como hoy ocurre con la parte palestina y su apoyo europeo.

Para el desarrollo del modelo interino a largo plazo es necesario otorgar un espacio de tiempo prudente, no limitado en el tiempo, pero tampoco extendido de forma infinita, en cuyo caso la pregunta 
es ¿cómo materializarlo? Los resultados obtenidos durante este acuerdo de suspensión de hostilidades en el tiempo serán los que marquen la senda de continuidad o no de las negociaciones de paz. Es decir, no hay fecha límite expresa para poner fin al diálogo, pero los acuerdos bilaterales directos entre las partes, así como los observadores de la Naciones Unidas, aportarán un diagnóstico sobre la conveniencia de la continuidad del acuerdo a largo plazo/interino durante periodos acordados entre las partes.

Debatir sobre a cuál de las partes pertenece Jerusalén tal vez llevaría otros sesenta años y no solucionaría el conflicto; sin embargo, si se analiza desde la perspectiva real y no emotiva, esto último es lo que ha venido haciendo Occidente y si abandona esta práctica puede que se logre llegar al consenso, que las partes inicien un diálogo creíble y creativo sobre la ciudad. En principio las partes, dentro de la negociación directa y el compromiso real, deben despojarse de prejuicios religiosos provenientes más de la historia.

También es necesario despojarse de la emotividad dentro de este conflicto, pues está claro que los choques de civilizaciones tienen su componente máximo en la religión que, según Huntington, va ligada al sistema democrático, así como a la resolución o no de los conflictos. A pesar de que el conflicto israelí-palestino logra convocar a todo el Islam, está claro que esta religión compacta en torno a ella los países que la integran, aun cuando entre estos mismos haya divisiones entre sunníes y chiíes, no ocurre lo mismo con los países occidentales e Israel cuando se supone que «democracia apoya democracia».

\section{Una administración bilateral para la ciudad}

Ante la negativa de ambas partes de ceder la administración de Jerusalén a modo de estatus internacional, se hace necesario ser creativos en lo que se piensa hacer, que ambas se hagan partícipes de la administración de la ciudad ¿cómo podría ser esto? La propuesta aquí descrita es que puede -según acuerdo de las partes- generarse una administración 
de dos formas: 1) unilateral con periodos intercalados temporales y 2) bilateral y de forma definitiva.

\section{Unilateral con periodos intercalados temporales}

Este modelo debe llevarse a cabo durante el tiempo que duren las negociaciones de paz dentro del modelo a largo plazo interino. Si bien una de las partes se niega a ceder su administración a Naciones Unidas, lo conveniente será que en principio ambas experimenten una administración dual. Cuando el primer ministro israelí Benjamín Netanyahu, en repetidas ocasiones ha expresado que Israel tendrá que hacer concesiones dolorosas, esta puede ser una de ellas. ¿Por qué no hacer el esfuerzo en aras de la paz? Otra cuestión distinta es, ¿̇a cambio de qué se hacen las concesiones? En este caso creo que la paz y la seguridad son razones suficientes para experimentar con este modelo.

Para tal efecto, será necesario escoger personas idóneas para ejecutar dicha administración sobre la ciudad, lo cual debe responder a que ambas partes de la negociación formulen los nombres de las personas que crean idóneas para este propósito, por lo que durante el periodos de acuerdo a largo plazo interino estos nombres no serán obtenidos por elección popular, pues lo que se hará será una prueba de validez o no de un modelo; que puesto en marcha deberá comprobar qué tan factible es que este tipo de administración se siga aplicando hacia futuro. De igual forma, serán las partes, con la ayuda de los observadores, quienes llegarán a un acuerdo sobre cuánto tiempo debe durará la administración de cada lado de la negociación.

Siendo la ciudad de Jerusalén el epicentro y fin último de este conflicto, y a pesar de su carácter religioso, este aspecto no debe constituirse en un inamovible dentro de las negociaciones de paz, ya que en esta ciudad convergen tres culturas, cada una de las cuales tiene no solo el legítimo derecho de acudir a ella y tener libertad de movimiento dentro de la misma, sino que también, la convicción por sus creencias, valores y principios, las hace depositarias del derecho a visitar los lugares santos de cada religión. 


\section{Bilateral de forma definitiva}

Esta otra posibilidad tendrá igualmente lugar dentro del modelo planteado y se dará si cada uno de los actores administra la parte de la ciudad que reclama como suya. Se entenderá como suya, aquellos barrios en donde sus habitantes representen mayoritariamente una u otra cultura. Ahora bien, estando en la ciudad la parte cristiana, dentro de este modelo deberá ser administrada políticamente por quien administre la parte judía, pues dada su cercanía cultural judeo-cristiana esto sería lo más lógico, ya que el cristianismo no está involucrado en el contencioso entre palestinos e israelíes por la ciudad.

Esta forma de administración sobre la ciudad de Jerusalén ha sido planteada, discutida y rechazada por las partes en anteriores ocasiones, pero no por ello debe ser obviada dentro del modelo de negociación que se ha propuesto. De hecho, dentro de este modelo pueden aplicarse con el consentimiento de las partes y el asesoramiento de los observadores propuestas legítimas que en el permanente distanciamiento de las relaciones entre palestinos e israelíes se han visto rechazadas. Insistimos, no por haber sido rechazada antes debe dejarse como tema ya abordado y decidido.

El plan de paz a largo plazo interino corresponde a lo que se puede denominar un laboratorio de paz, aplicado en países que padecen conflictos, como el caso de Colombia, aunque un conflicto y otro disten de ser parecidos. Sin embargo, en este modelo la experimentación de diversas situaciones, dentro de los factores de tiempo y espacio, es susceptible de albergar nuevas situaciones que puedan llevar a comprobar la posibilidad de una futura solución pacífica al conflicto israelí-palestino. A pesar de la negativa en repetidas ocasiones, por parte de los actores de las negociaciones, la administración bilateral de Jerusalén puede estar más cerca que ninguna otra de constituirse en una solución para la ciudad, además, este modelo incluye la fijación de unas fronteras reales de la ciudad, es decir, la inclusión de los asentamientos en Cisjordania (Judea y Samaria).

He de reconocer que queda el interrogante de la capacidad de la parte palestina para no perder el control en una determinada administración de los barrios árabes de la ciudad, si este territorio llegará a 
caer en manos de Hamas es claro que los cristianos y judíos no podrían transitar por dicha ciudad. Si he de ser realista, no creo posible que en una administración de la parte árabe por miembros de Hamas exista incluso libertad para los propios palestinos del otro lado, por lo que habrá que asegurarse de que la parte árabe sea administrada por la AP.

\section{Derecho de retorno}

Es necesario entender, a propósito de esta pretensión, que se ha puesto sobre la mesa como punto de intercambio por otros temas, dado que es inconcebible pretender regresar a unos hogares que en muchos casos ya no existen, por lo que pensamos que esta pretensión no refleja del lado palestino un deseo real de avanzar en el diálogo. Este punto, más que un tema real de discusión, procede en la mesa de diálogo como un tema más bien encaminado a ser utilizado para conseguir de la otra parte la cesión de algunas de sus pretensiones. De acuerdo con lo anterior, mi perspectiva visualiza la imposibilidad del derecho de retorno. Sobre la base del realismo a partir del cual se diseñó este modelo es imposible pretender un retorno total de los refugiados árabes y sus descendientes, que también ostentan el mismo nivel. Este punto, que está dentro de los que históricamente han trabado el conflicto, pertenece a los denominados estructurales profundos, por su cariz cultural. El grado de conflictividad que contiene este punto no es menor al de otros de su misma estructura.

Si este modelo está basado en el realismo, se debe comenzar por hablar con claridad, ante la imposibilidad de llevar a cabo un movimiento de personas que hoy la Agencia de Naciones Unidas para los Refugiados Palestinos (UNRWA) considera que son unos cuatro millones de palestinos, y considerando que la población israelí oscila entre 7 y 7.5 millones de personas, el retorno se hace imposible en su totalidad como pretende la AP.

Tal vez sería posible llegar a un acuerdo sobre ¿cuántos y qué tipo de refugiados puedan entrar en Israel? Esta posibilidad surge por cuanto tendría que analizarse de qué generación de refugiados estamos hablando, recordemos que hoy ya están en la tercera generación. 
A esto hay que adicionar, ¿dónde van a ser instalados? Pues la AP afirma que le deben ser devueltas sus casas porque incluso algunos aún conservan las llaves de las mismas, cuestión esta también imposible, pues gran parte de ellas ya no existen.

Lo anterior conduce a varias preguntas obligadas para este punto: ¿quién es considerado y por qué un refugiado palestino? ¿Quién es un palestino? ¿Por qué el tratamiento que otorga las Naciones Unidas a un refugiado palestino es distinto a los otros refugiados del mundo? Sin duda, hoy los refugiados afganos, iraquíes, africanos, sirios y latinoamericanos no tienen un estatuto aplicable igual que los refugiados palestinos. Estos últimos están bajo la jurisdicción del Organismo de Obras Públicas y Socorro para los Refugiados Palestinos en el Medio Oriente (OOPS), los «otros» están bajo la jurisdicción del Alto Comisionado de las Naciones Unidas para los Refugiados (ACNUR).

En cuanto a ¿quién es un refugiado palestino? se tiene como base para estos efectos la definición de la UNRWA, que es la agencia de la Naciones Unidas encargada de todo lo concerniente a los palestinos refugiados, quien, sin perjuicio de un acuerdo entre las partes, conceptúa lo siguiente:

1. Refugiados palestinos son aquellas personas cuya residencia habitual entre el 1 de junio de 1946 y el 15 de mayo de 1948 era Palestina,

2. Los que perdieron sus hogares y medios de vida a consecuencia del conflicto de 1948.

3. Los que se refugiaron en alguno de los países o regiones donde opera la UNRWA,

4. y los descendientes por línea masculina de las personas que cumplen los requisitos de 1 a 3. Como vemos por esta definición, la nacionalidad actual no tiene mucha importancia en la definición de refugiado palestino, tanto si la inmensa mayoría de los refugiados han adquirido la nacionalidad del país anfitrión (Jordania) como si solo lo ha hecho una minoría insignificante (Siria) o una proporción intermedia (Líbano). (Courbage, 2004). 
Sin embargo, la disparidad de criterios que indican quién debe tener el estatus de refugiado palestino ha impedido la uniformidad de cifras, por lo que sería conveniente dentro del acuerdo de negociación una comisión especial, integrada por miembros de ambas partes del conflicto, que dedique tiempo y espacio exclusivamente a la conformación de criterios y análisis de cifras. De tal forma que el estudio del tema tenga en cuenta la realidad actual.

Algo en lo que sendos investigadores y estudiosos han convenido, es que existe la imposibilidad de que el derecho de retorno se le pueda aplicar a todos los refugiados palestinos, pues al tiempo que los refugiados alegan que es su derecho inalienable, los israelíes afirman que de aplicarse el derecho de retorno el carácter judío de Israel se vería afectado. No obstante, se debe tener en cuenta este punto, pese a la sensibilidad que despierta en ambos lados de las negociaciones, pues es necesario considerar la posibilidad de que los observadores de la ONU aporten asesoría al respecto, aunque la fórmula de aplicación del derecho solo deberá ser decidida y delimitada por las partes.

Dentro de las negociaciones a largo plazo interino que se deben desarrollar a ambos lados de los territorios en disputa, este punto puede en principio empezar a negociarse desde la siguiente premisa: "Sin embargo, para que se pueda ejercer este derecho hay que llegar a un acuerdo político, basado en la distinción entre el reconocimiento del derecho y su aplicación, entre el retorno a un Estado palestino y las posibles formas de retorno a Israel» (Sitta, 2004).

El acuerdo político entre las partes más que básico es necesario, pues de esto dependerá el avance de este punto dentro del modelo. Ahora bien, en las negociaciones que se desarrollen referentes al retorno de los refugiados, tendrá que llegarse a una espacie de acuerdo en cuanto a quién se le reconocerá este estatus. Para lo anterior es de suma importancia actualizar cifras, ya que son varias las organizaciones que las manejan, así como reconocer una sola base de datos para la negociación de este punto.

En síntesis, este modelo propone que se tengan en cuenta las siguientes premisas para la negociación de este punto: 
1. Una selección demográfica de aquellos segmentos de la población palestina que serían reconocidos con el estatus de refugiado.

2. Que el retorno de los refugiados (si se diera) se enmarque dentro de aquello que según las negociaciones se constituirá como el Estado palestino.

3. La constitución de un fondo económico de compensación por parte del Estado de Israel para reparar aquellos palestinos que sean cobijados con el estatus de refugiado. Incluso, este fondo podría estar a cargo de una mesa de donantes internacional.

\section{Selección demográfica}

Se propone la concreción de aquellos criterios que las partes en común reconocerán a las personas poseedoras de este derecho, tales como, fecha de salida de sus hogares, pertenencias al momento de abandonarlos (dinero, muebles y enseres, tierra y casa), adicionalmente, la edad de los reconocidos como refugiados deberá estar en consonancia con la fecha en que salieron de Palestina. Este apartado consagra la necesidad de un riguroso estudio historiográfico para avanzar en el reconocimiento de los refugiados palestinos, pues de otro modo las complicaciones serán innumerables. Se ha mencionado anteriormente que solo se debe tener en cuenta para el reconocimiento del estatus de refugiado el concepto de la UNRWA, sin perjuicio de lo que las partes acuerden en las negociaciones de paz.

El acuerdo a que lleguen las partes, a través de este modelo, procurará recopilar la mayor cantidad de información, de tal forma que pueda hacerse un minucioso estudio comparativo con las cifras manejadas por la UNRWA y otras organizaciones. Lo anterior, teniendo en cuenta que no es secreta la existencia correlativa de innumerables estadísticas que incluso incluyen dentro de este estatus a quienes huyeron de la zona cuando cayó el Imperio Otomano y empezó el Mandato Británico. Un caso concreto es el Palestinian Central Bureau of Statistic que maneja sus propios números y criterios para la selección del estatus de refugiado palestino, diferentes a los que emplea la UNRWA. 
Otro escollo no menos importante en este punto, y que tal vez debe resolverse antes que cualquier otro, consiste en definir ¿quién es palestino?

La falta de homogeneidad en las definiciones de "palestino" produce una confusión inevitable en las estadísticas. Pero el problema no acaba ahí. También puede ser político. El país de acogida de la diáspora palestina más numerosa, Jordania, no ha publicado cifras referentes a ese segmento importante de su población, a pesar que el censo de 1994 figuraba el lugar de nacimiento de la persona y sus ascendientes (Courbage, 2004).

Extenderse en este tema, enumerando la infinidad de estadísticas que hoy existen, sería inútil, pues lo que se quiere, además de avanzar, es obtener datos limpios, no repetidos y creíbles; de tal forma que la negociación de este punto estructural profundo no termine favoreciendo a personas equivocadas y desfavoreciendo a ambas partes.

\section{Retorno de los refugiados palestinos a un Estado palestino}

Si hoy la AP pide ante la ONU el reconocimiento de un Estado Palestino como miembro de pleno derecho en esa organización, la misma AP debe entonces propugnar porque sus ciudadanos vivan en el territorio que será su Estado, pues no tiene sentido reclamar el reconocimiento de un Estado si sus miembros no van a habitar en él. De tal forma que, si actualmente tanto Gaza como Cisjordania (Judea y Samaria) están bajo gobiernos de ciudadanos palestinos, se entenderá que ambos han dejado de ser campamentos de refugiados.

Cuando se hace referencia a la prácticamente imposibilidad de un regreso a sus antiguos hogares por parte de quienes huyeron durante 1948, se habla de una realidad que se hace inherente a las negociaciones de paz en este modelo. No tendría sentido el dialogo si no se basa en la realidad misma, por lo tanto, y teniendo en cuenta el estado de 
la cuestión, así también serán las bases sobre las cuales se va a construir un Estado palestino.

De nada serviría sentarse a negociar la paz, si lo que se pretende es que las cosas continúen tal como están. Con el acuerdo a largo plazo interino que proponemos, lo que se quiere es construir un Estado palestino establecido sobre unas fronteras reales y creíbles, despojando toda pretensión del aspecto cultural, algo imprescindible para consolidar una paz duradera.

Una cuestión que se debe analizar en este punto, para luego llevarla a las negociaciones, es la posibilidad de trabajar sobre la idea de que existan algunos palestinos que no quieran regresar. Esta posibilidad no debe descartarse. Si bien es cierto que generalmente quienes escriben e investigan sobre el tema, poco o nada consideran esta posibilidad, este modelo propone tenerla en cuenta toda vez que personas denominadas palestinas no solo se han asentado en los campamentos de refugiados, también los hay en países de Europa, Estados Unidos, Latinoamérica, incluso dentro de Israel y otras regiones del mundo.

Esta posibilidad del no regreso es absolutamente real, toda vez que, si se materializa, muy seguramente alteraría la multiplicidad de estadísticas que hoy se manejan, aclarando que puede ser que existan palestinos que no deseen regresar, pero que de igual forma esto sería sin perjuicio de una posible indemnización. Cuando la AP, e incluso Hamas, reivindica el reconocimiento de un Estado palestino, no menos lícito es que lo haga la otra parte, Israel. Por otra parte, la organización de la población en su Estado estará a cargo de los mismos palestinos, sin perjuicio de que otros organismos quieran participar, pero será de igual forma objetiva en no lesionar los intereses israelíes o, lo que es lo mismo, no violentar el acuerdo a que lleguen las partes.

La realidad actual nos muestra que para que todo esto suceda habrá un movimiento de personas tal como en su momento ocurrió en los Balcanes, o en Grecia y Turquía, al final de la I Guerra Mundial, o como sucede hoy con los refugiados sirios que entran a Europa y los que son devueltos a Turquía. Por lo tanto debe procurarse que una vez iniciada la negociación, este punto no entre en un espacio muerto que permita prolongar la vida en los campos de refugiados como un hecho consumado, que es lo se ha venido haciendo hasta hoy. 
Sin embargo, este punto no es menos complicado y si bien hemos mencionado los ejemplos anteriores de «traslado» de personas, esto no significa que todos sean iguales o tengan los mismos resultados, el caso del conflicto israelí- palestino puede llegar a ser el más complicado, entre los puntos que deben ser analizados para este propósito encontramos la economía, las condiciones en lo que hoy son los territorios palestinos no pasa por un situación capaz de soportar la incorporación de una mano de obra masiva, mucho menos cuando ésta no es mayormente cualificada.

La encuesta de población activa de 1998 arrojaba una tasa de paro de $23 \%$ en Gaza y $13,2 \%$ en Cisjordania, que al sumar el subempleo ascendía a $25 \%$ y $21,4 \%$ respectivamente. Una encuesta más reciente, realizada en primavera de 2001, revelaba que a seis meses del estallido de la segunda intifada el $11 \%$ de las familias había perdido su fuente de ingresos, el salario medio mensual había menguado un $48 \%$ y el $64 \%$ de la población vivía por debajo del umbral de pobreza. (Fargues, 2004).

De acuerdo con lo anterior, la situación actual de los refugiados palestinos no sería la mejor ni siquiera en su posible propio territorio, por lo que, el retorno de los refugiados, siendo uno de los puntos más delicados, necesitará, para su debate, tiempo suficiente como para el alcanzar el consenso entre las partes. Es de vital importancia estudiar todas las posibilidades creíbles que han sido propuestas desde el inicio del conflicto hasta hoy, de manera que no se creen falsas expectativas que generen más incertidumbre; si hay un punto delicado para su estudio y solución es este, por lo que, en ese sentido, nuestro método se apoya en la negociación a largo plazo, exenta de caducidad.

La situación política en lo que hoy son territorios palestinos no es de unidad, por lo que también esto dificulta la aplicación del derecho de retorno, pues al anexar un número de personas a un futuro Estado palestino nadie puede garantizar la unidad de dicha sociedad. Además, teniendo en cuenta que en Gaza la situación política es distinta que en Cisjordania (Judea y Samaria) y muy seguramente lo seguirá siendo, 
será difícil garantizar a los israelíes el pleno de seguridad en las fronteras con un futuro Estado palestino, mucho menos se podrá garantizar la seguridad del Estado de Israel, que puede verse en riesgo por la entrada de refugiados, que hoy podrían pertenecer a grupos fundamentalistas.

Tiene una gran importancia dentro de la posible solución, pues beneficiará al mismo tiempo a las partes de la negociación, a los palestinos el derecho a un Estado y a los israelíes el derecho a su seguridad, o lo que es lo mismo el derecho a su existencia como nación. En caso de que se llegase a un final positivo entre las partes, quedaría pendiente el encargo de llevar a cabo este movimiento de personas sin que esto perjudique el acuerdo mismo. La cuestión de cómo y cuánto tiempo tomaría este «traslado» de personas es en extremo delicada y deberá ir acompañada de interrogantes como: ¿qué tipo de retorno será: real, simbólico o una combinación de ambos?

Este modelo de acuerdo a largo plazo contempla la posibilidad de que sea Naciones Unidas quien supervise este tema, a través de la propia UNRWA y con el apoyo económico de países donantes, que incluso podrían ser los miembros de la Liga Árabe, de tal forma que esta llenaría de alguna forma su deficitaria participación dentro de las negociaciones de paz hasta hoy.

\section{Fondo económico de compensación israelí}

Sobre la base de que ningún conflicto es igual a otro, por lo tanto sus soluciones también distan de serlo, y sin querer equipar el Holocausto (Shoa) con la cuestión palestina, el modelo a largo plazo interino propone la adopción de este fondo económico de compensación para aquellos casos en los que sea imposible llegar a un acuerdo en cuanto al retorno. Este sistema fue puesto en práctica por Alemania para compensar no solo a sus ciudadanos judíos sino a otros grupos humanos que fueron víctima del régimen Nazi.

Este punto no es nuevo en el plano de las negociaciones, es tal vez el más antiguo, si tenemos en cuenta que desde la guerra entre árabes e israelíes de 1948 a 1949 se han elaborado sendos planes para resolver esta cuestión, así como sendas propuestas que han rechazadas por 
ambos lados del conflicto. La propuesta de la posible indemnización causó polémica, en principio, aunque de igual forma fue el embrión que hizo surgir décadas después la premisa de «tierra por paz».

En principio, Naciones Unidas delegó el estudio de la posibilidad de indemnización a la UNCCP, quien recibió el mandato específicamente «técnico» de su función, para lo cual designó en 1950 a tres expertos que pudieran dar luces sobre esta cuestión, Holger Andersen, Servoise y Tevfik Erim. Como casi todo lo que ha rodeado el tema de la indemnización, esta comisión fue tan efímera como las distintas propuestas que en su momento se esbozaron.

Los distintos planes de indemnización fueron rechazados y ninguno se llevó a cabo. En consecuencia, este modelo propone estudiar aquellos puntos que se consideren creíbles y aplicarlos hoy al proceso de paz. No es absolutamente necesario volver a buscar puntos de estudio, aunque no se descarta que la existencia de estudios preliminares sirva para construir, sobre estos insumos, las vías sólidas para lograr el consenso de las partes.

También se puede trabajar sobre aquellos puntos adecuándolos a la realidad actual y analizando los pros y contras, con el fin de examinar la situación interna de ambas partes y de la región. Esto último es esencial, pues como hemos afirmado antes la solución o no de este conflicto afecta no solo a las partes sino a la región.

Los puntos anteriores constituyen lo que puede ser un principio de acuerdo dentro del lapso en que se desarrollen las negociaciones a largo plazo. Si estos puntos básicos llegan a obtener el consenso de las partes, se estima que sería una forma de abrir el camino hacia temas igualmente complejos. Sin duda, esto equivaldría a ir un paso adelante dentro del reconocimiento de la posibilidad de negociar sobre la realidad $\mathrm{y}$, especialmente, tratando de proteger a los que necesitan una asistencia más urgente, es decir, a los refugiados, de forma tal que se alivie su situación y que este hecho contribuya a aportar soluciones humanitarias.

La propuesta puede abrir subsidiariamente una vía para el consenso en cuanto a quiénes deben regresar a territorio de un futuro Estado palestino y quiénes no (teniendo en cuenta la decisión unilateral de cada persona). Sin embargo, insisto, todo punto de negociación debe ser tratado directamente entre las partes de la negociación, por 
lo que el modelo de indemnización no está exento de dificultad dada la complejidad del conflicto. Dentro del punto de la indemnización va inmerso también el retorno o no retorno, lo cual ha dificultado el consenso entre las partes, pues de un lado se pretende que uno lleve al otro (palestinos) y del otro se refuta la imposibilidad de que ambos puntos se entremezclen (israelíes).

Algunos de los interrogantes que surgen con respecto al tema de las indemnizaciones son, entre otros:

- ¿A partir de qué fecha se debe indemnizar?

- ¿Qué tipo de indemnización se hará: individual (es decir para cada persona), colectiva o a Palestina como Estado?

- ¿Qué se va a indemnizar: bienes, muebles, inmuebles, perjuicios?

- ¿En qué moneda se hará la indemnización y si habrá indexación?

Estas son apenas algunas de las preguntas que han surgido respecto a este punto -por parte de Naciones Unidas, la UNCCP y los distintos expertos- que no han dejado de ser un escollo para llevar a cabo la figura de la indemnización. En el primer interrogante se ha discutido si la fecha debe ser desde los datos que se tienen del Mandato Británico, anterior a ello (Imperio Otomano) o después de la guerra de 1948.

En cuanto a qué tipo de indemnización se hará, es importante aclarar que no solo hubo discordancia entre las partes sino dentro de la comunidad árabe, que entonces no lograba ponerse de acuerdo sobre este punto, pues tanto la indemnización individual como la colectiva tuvieron simpatizantes. Incluso en septiembre de 1949 la misión Clapp recomendó, después de finalizar un estudio, que la indemnización debía ser de carácter global y no individual. Esta propuesta tampoco logró que las partes llegaran a un acuerdo, pues mientras los árabes propendían por las dos, los israelíes aducían que se tuviera en cuenta el periodo de guerra, lo cual significaba que se debían distribuir las indemnizaciones de forma regional, ya que la contraparte en la guerra fueron países árabes, lo que significaba que estos últimos también habían destruido fincas en territorio palestino.

Se podría citar un sinnúmero de cifras que se propusieron entonces y en décadas posteriores, pero esto no aportaría nada a la solución de este punto, pues el propósito es insistir en la necesidad de abordar 


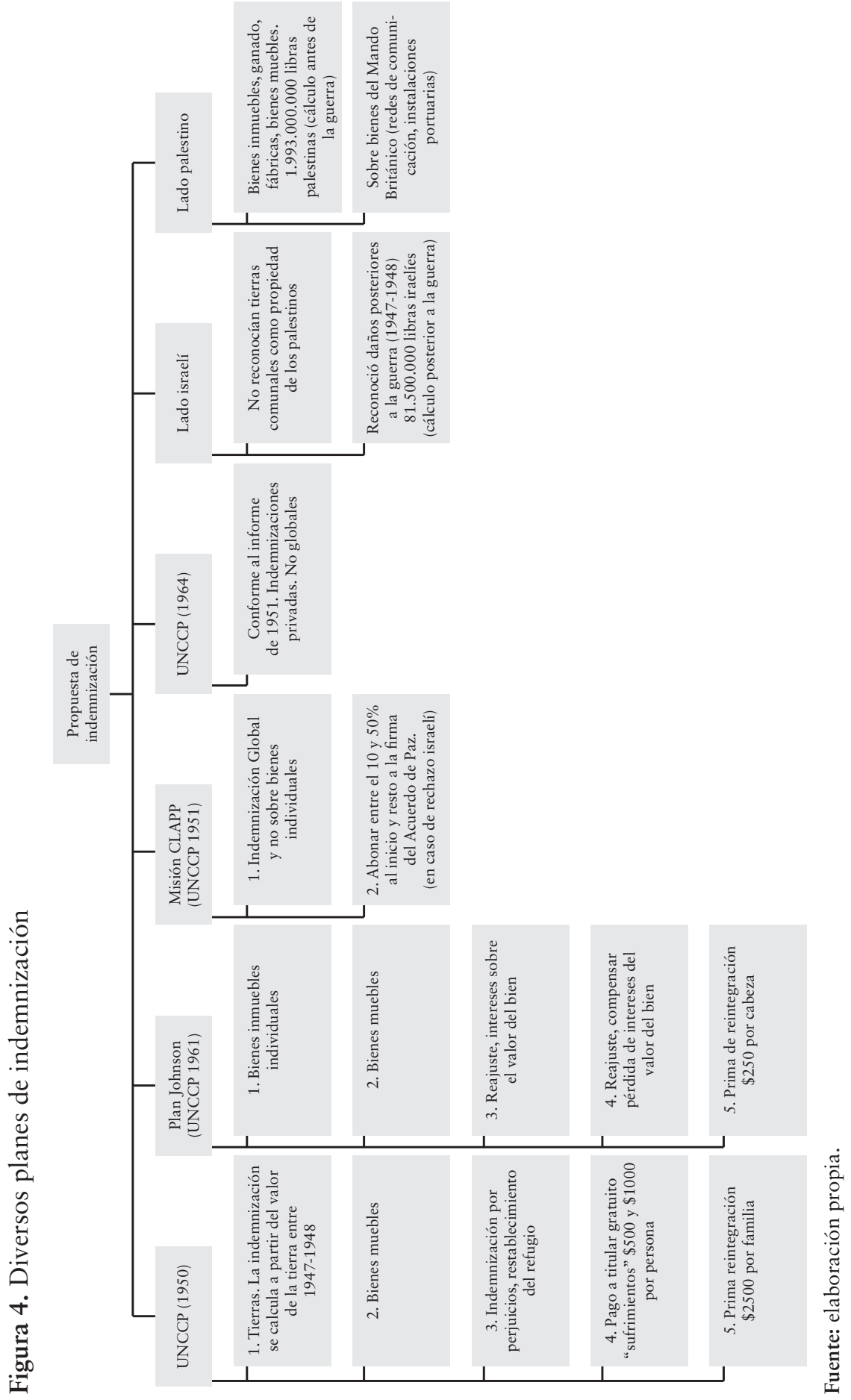


el tema. Incluso de este punto depende, en gran medida, la realidad socio-política y de seguridad no solo del Estado de Israel sino de la región. Dado que la región será la más beneficiada, es una necesidad incorporar a los países árabes que hoy tienen refugiados palestinos en la negociación de este punto, pues si bien ellos han soportado parte de la carga, no económica pero sí territorial, es necesario que tengan voz, ya que son los directamente afectados.

En los países árabes que hoy albergan refugiados palestinos puede estar la clave de la solución de este punto, pues podrían participar directamente incorporando propuestas y proponiendo soluciones reales y creíbles a los tiempos de hoy. Este modelo propone, en ese sentido, que la Liga Árabe participe de este punto, a fin de destrabar las distintas objeciones que se han venido presentando sobre esta cuestión desde finales de la guerra de 1948 y dentro de la misma población árabe palestina.

Este modelo entraría a las negociaciones en los casos en que sea imposible, después de toda negociación, llegar al consenso entre las partes, es decir, no actuaría como un factor auxiliar sino autónomo. En las negociaciones de Taba en 1991 se propuso este modelo, pero no se llevó a cabo; hoy, ante la dilatación del proceso de paz y la traba cada vez mayor del conflicto, esta posibilidad debe ser analizada de tal forma que pueda ser vista como una posibilidad real. En 1949, en la Conferencia de Lausana, también se propuso la indemnización de los refugiados palestinos, incluso de aquellos que no quisieran regresar.

Dentro de este modelo, el sistema, al ser autónomo, constituye por sí solo una ventana para los casos que sean imposibles de resolver. Lo proponemos de esta manera porque nada es descartable dentro de este conflicto, pues hay necesidad de negociar sobre la realidad. Entonces en Lausana se propuso:

Estudiar el problema y las medidas concretas que deban tomarse en cuenta para pagar e indemnizar a los refugiados que opten por no regresar a sus hogares, y por la pérdida o destrucción de sus bienes que, en virtud de los principios de las leyes internacionales o por razones de equidad, deberán ser reembolsados por los gobiernos o las autoridades responsables. (Fischbach, 2004). 
Ni en el año 1949 ni en las negociaciones de Taba, se llegó a un acuerdo entre las partes en lo que concierne a este tema. En ese entonces Israel se retiró de la comisión mixta árabe-israelí que lo estudiaba; sin embargo, dentro de nuestro modelo, actualmente es necesario regresar a este tema y a las negociaciones, pues las condiciones de la región son otras y los peligros que afronta el propio Israel también. El modelo a largo plazo interino incorpora no solo a aquellos que unilateralmente opten por el no regreso, sino que adiciona a aquellos casos imposibles.

Los casos que he denominado imposibles de resolver, no serán otros distintos a los que surjan de la negociación sobre la delimitación de fronteras, que al diseñar un modelo desde el realismo no descartamos que surjan, incluso esperamos que surjan, pues como he mencionado anteriormente el conflicto israelí- palestino está en constante mutación y nada debe ser descartado. En el año 2005 el primer ministro Ariel Sharon llevó a cabo la desconexión de Gaza, cuando ni los propios palestinos lo esperaban.

\section{Los asentamientos}

Este tema va inmerso dentro de las negociaciones de las fronteras, por lo que podría denominarse un tema subsidiario, lo que no lo hace menos importante y delicado para las partes, pues, de cierta forma, cuando se llegue a un acuerdo sobre las fronteras finales podríamos estar hablando de un determinado número de israelíes que también deberán «retornar» al interior de las fronteras de Israel. Este punto es subsidiario por su dependencia con la solución de fronteras, lo que hace que en el último proceso de negociación, según el presidente de los Estados Unidos, la solución de esta cuestión va inmersa dentro del tema de fronteras, que sería sobre el reconocimiento por parte de Israel de las fronteras anteriores a 1967 y que este último rechaza.

"Las fronteras de Israel y Palestina deberían de estar basadas en las línea de 1967, con intercambios mutuamente aceptados”, manifestó. Aunque no presentó específicamente un plan de paz, Obama estableció las fases en las que se debe de hacer esa negociación, 
dejando los delicados problemas de la capitalidad de Jerusalén y el regreso de los refugiados palestinos para una segunda etapa.

(Caño, 2011).

Posterior a esta manifestación, hecha por parte del presidente Obama, el gobierno israelí descartó de tajo esa posibilidad, entrando nuevamente el conflicto en una fase de congelamiento que persiste hasta hoy. No es posible para la solución de un conflicto partir de una posición unilateral, menos aun cuando quien lo plantea es el tercero mediador. Este punto estructural profundo es uno de los que ha hecho del proceso una negociación prolongada e incierta, ¿con o sin futuro? Depende de las partes.

Actualmente existen 120 asentamientos israelíes registrados dentro de lo que las partes reclaman como los territorios en disputa, lo que haría necesaria una posible partición del territorio donde estos asentamientos se concentran. El tema de los asentamientos dentro del modelo de acuerdo a largo plazo interino debe, en primera medida, llevar inmersa la congelación de los que están proyectados y de los que posiblemente se lleguen a aprobar para su construcción.

La congelación es necesaria para generar credibilidad en la negociación de paz y la legitimidad de la parte israelí dentro del proceso. De esta forma, en la última negociación de paz, presidida por el presidente Obama, el primer ministro Netanyahu congeló durante 10 meses la construcción de asentamientos, aun con la dificultad que dentro de su propio gobierno le generó. En consecuencia esta congelación puede volverse a dar durante el tiempo en que se lleven a cabo las negociaciones de paz, con el compromiso previo de que las negociaciones deben ir dirigidas a obtener un resultado concreto. Aunque es importante aclarar que este no es un conflicto inmobiliario, como muchos lo han querido ver.

También es necesario generar un compromiso previo a la obtención de resultados, pues en las últimas negociaciones de paz las partes llegaron divididas a la mesa de diálogo, lo que se reflejó en los nulos resultados obtenidos, ya que una de las partes abogó por un compromiso previo de prórroga de la congelación (AP) y la otra parte se negó a circunscribir dicha prórroga. Para este punto, si se pretende una solución 
real y creíble, se debe apostar por propuestas que, si bien pueden llegar a ser juzgadas como de arriesgadas, deben formularse dentro del acuerdo a largo plazo e incluir los aspectos descritos a continuación.

\section{a) Intercambio de tierra}

Es factible estudiar y analizar qué puntos primarios (en cuanto al orden de negociación) pueden ser intercambiados por territorio, es decir que la seguridad de los israelíes sea garantizada tanto como la materialización de un futuro Estado Palestino libre de grupos terroristas. En este sentido, las peticiones pueden ser intercambiadas de acuerdo con lo que representen en materia de seguridad para unos y de un futuro Estado para los otros. Esto se haría con el fin de equilibrar las cargas, pero también las consecuencias de las pretensiones, es decir, la tierra que pretenden unos a cambio de las pretenciones del otro.

Siendo la tierra uno de los puntos más sensibles, pues ha llevado a que dos culturas pretendan el mismo espacio geográfico, dentro de este intercambio necesariamente se deberá analizar la situación real y actual del conflicto, lo que incluye la actual geopolítica de la región en las negociaciones de paz. Esto necesariamente conlleva -como se he mencionado antes- buscar soluciones que involucren a la región; por ejemplo, el tema de seguridad se debe analizar desde lo regional, dada la amenaza en seguridad que representa hoy Irán, no solo para Israel, sino para toda la región.

Este punto de intercambio de tierras es susceptible de aplicarse al tema de seguridad, si se plantea la seguridad esgrimida por el Estado de Israel para garantizar su existencia. Así, por ejemplo, algunas de las tierras habitadas en los asentamientos pueden ser intercambiadas por otros puntos dentro de la negociación de paz. Si bien en este conflicto se aborda esencialmente el tema de la tierra, no hay que olvidar que la solución de unas probables fronteras lleva también inmersa aspectos tales como el mar y el aire, que seguramente entrarán en las negociaciones de paz. Por otro lado, los asentamientos pueden estar dispersos en pequeños poblados como Cisjordania o, por el contrario, en auténticas ciudades como el de Ariel o Maale Adumim al Este de 
Jerusalén. Podríamos hablar de un total de 120 asentamientos, denominadas como legales por ser construidos bajo la ley israelí, aunque estos no son los únicos.

Este punto, como se ha mencionado al principio de la exposición del modelo, también deberá ser tratado con los habitantes de los asentamientos y los palestinos; al ser ellos los directamente afectados, sus propuestas deberán ser tenidas en cuenta, pues no todos los colonos están depuestos a usar la fuerza ni todos los palestinos a atentar contra estos. Lo anterior no es óbice para pretender que no haya de cada lado del conflicto quien sí esté dispuesto a arriesgar hasta último momento para evitar el intercambio de tierra.

\section{b) Intercambio de tierra por manejo de seguridad en mar y espacio aéreo}

Se propone la posibilidad de la liberación de tierra por parte de Israel, a cambio del manejo de la seguridad en lo que sería el espacio aéreo, y en las aguas marítimas de un futuro Estado palestino. Cuando se ha hablado acerca de decisiones arriesgadas, me refiero a este tipo de decisiones, aquellas que no solo serán dolorosas para ambos lados de las negociaciones de paz, sino también arriesgadas por lo complejo del conflicto, ya que igual de compleja está siendo y seguirá siendo la búsqueda de una solución pacífica.

Si en 2005 Israel llevó a cabo la desconexión de Gaza de forma unilateral, es necesario nuevamente llegar a un acuerdo para aplicar la desconexión en Cisjordania (Judea y Samaria), de tal forma que se llegue al intercambio de tierra por elementos fundamentales para la seguridad israelí y la fundación de un futuro Estado palestino. El punto de los asentamientos está ligado al de las fronteras que deberán ser definidas de acuerdo con la solución que se produzca sobre los asentamientos. La propuesta de control del mar y el espacio aéreo palestino, por parte del Estado de Israel, se justifica en la seguridad de los israelíes, pues es necesario garantizar este punto para que el lado israelí ceda en todo o en parte a las propuestas del lado palestino. 
Los puntos básicos estructurales de aguas marinas y espacio aéreo ya fueron pactados por las partes en el acuerdo Gaza-Jericó en 1994, celebrado en la ciudad de El Cairo, que al mismo tiempo entregó la autoridad civil administrativa a la AP de Cisjordania y Gaza.

En materia de seguridad, el acuerdo Gaza-Jericó contempla, entre otros puntos, el siguiente: «Seguridad Externa: Israel mantiene el control de seguridad y la supervisión sobre la entrada de personas, vehículos y armas en todos los puntos de entrada. Israel mantiene el control del mar, así como el control y la supervisión de todo el espacio aéreo» (Ministry Foreign Affaire, 2011).

Este punto del acuerdo -aún vigente- debe ser ratificado en las negociaciones de paz, pues, dada la situación en la región, de pasar las fronteras marítimas y aéreas a manos de un futuro Estado palestino la seguridad de ambos países estaría en peligro. Hoy la situación en la región ya no es solamente preocupante para Israel sino para los propios países árabes que ven en ascenso la influencia iraní, así como el de su programa nuclear en la zona y el empoderamiento de grupos yihadistas como el Daesh. Este modelo de negociaciones de paz lleva intrínseco el factor realismo, por lo que este punto, al igual que los anteriores, debe basarse en el principio de la realidad actual de una de las zonas más complejas y volátiles del mundo. Además, dada su importancia geoestratégica es necesario que la seguridad de esta zona específica quede en manos del Estado que pueda enfrentar las amenazas externas, que no son pocas y sí muy frecuentes.

Una de las amenazas que se deben neutralizar, y que un futuro Estado palestino no estaría en condiciones de garantizar, es el tráfico de armas entre Gaza y Egipto. Una paz creíble, en este punto de las negociaciones, tiene que considerar la definición de las fronteras, pues, como se ha dicho en párrafos precedentes, este ha sido uno de los principales errores del plan de paz del presidente Obama, ya que este afirma que las fronteras deben ser definidas desde las fronteras anteriores a 1967. Esta última propuesta desconoce que la situación y la seguridad no son las mismas a las que había en 1967, por lo que es poco probable avanzar en una negociación de paz a partir de lo ocurrido en dicha fecha. Lo mismo ocurre con el aspecto demográfico, aunque no lo denominaremos como otros anteriores, imposible, sí 
puede estar cerca de serlo, pues la población israelí tampoco es igual en número y estructura habitacional a la de aquel entonces.

En síntesis, el punto de los asentamientos es indivisible del de las fronteras definitivas para la solución del conflicto. La construcción de nuevos asentamientos no puede ser una excusa para congelar las negociaciones de paz, pues estos pueden ser desmantelados de la misma forma que ocurrió con los de Gaza en 2005. Entonces los puntos principales del acuerdo fueron: seguridad, asuntos civiles, cuestiones legales y relaciones económicas.

El espacio aéreo y las fronteras marítimas, dentro de esta propuesta de manejo israelí, deben ser materializados en sentido de concesión, es decir, por un tiempo prudente acordado por las partes, con la participación de los observadores de Naciones Unidas en materia de seguridad, teniendo como base la seguridad israelí y la protección al Estado palestino.

\section{Sistema de concesión de seguridad}

La propuesta de intercambio de territorio por una concesión de seguridad en el espacio aéreo de un futuro Estado palestino y sobre aguas marítimas deberá ir acompañado de un análisis previo de riesgos y amenazas vigentes y futuras, que arroje como resultado un programa de seguridad creíble y sólido que se aplique, como mínimo, durante quince años. Este deberá ser prorrogado por una vez y ser materia de estudio antes del vencimiento de la prórroga para una posible prórroga según sea la situación de riesgos y amenazas previsibles en la zona. Dicha prórroga y sus causas deberán ser analizadas y debatidos en el CSONU con la intervención de las partes; de igual forma, deberá ser ratificada por este organismo, no sin la anterior aceptación de las partes.

Si la paz ha sido esquiva por seis décadas dentro del conflicto israelí-palestino, no es posible concebir un tiempo de concesión de seguridad, en manos del Estado de Israel, de por lo menos la mitad del tiempo que hasta hoy lleva el conflicto. Teniendo en cuenta la importancia de Oriente Próximo para el resto del mundo y dado que uno de los puntos de desestabilización, aunque no el único, es este conflicto, 
en ello se basa esta propuesta de concesión de seguridad, de tal forma que la influencia iraní en la región y específicamente en la parte que tiene que ver con este conflicto, Líbano, Siria y Gaza tienen asentados en sus territorios sendos grupos terroristas patrocinados por Teherán.

El programa nuclear iraní representa un alto grado de amenaza para la zona, por lo que debe ser uno de las principales puntos de negociación para alcanzar la paz entre israelíes y palestinos. Esto último teniendo en cuenta que "según el concepto de seguridad aplicado a Gaza y Jericó, estas áreas se consideran parte de la "cobertura" de seguridad israelí» (El acuerdo Gaza-Jericó, Israel Ministry Foreing Affaire, 2011). De igual forma se puede extender este acuerdo sobre la totalidad del espacio aéreo palestino, bajo el modelo de concesión.

Bajo la figura de acuerdos de seguridad contemplada en el Acuerdo Gaza- Jericó otorga la seguridad de cada parte por su propia cuenta, es decir, la seguridad de los asentamientos israelíes, al gobierno israelí y la seguridad de los palestinos corresponde a la AP; sin embargo, la seguridad externa se otorga al Estado de Israel. El acuerdo firmado por Arafat y Rabin, bajo el auspicio del gobierno de los Estados Unidos, nos aporta una puerta de entrada a la firma de un acuerdo final dentro de la negociación de paz.

Ya que la seguridad es un tema tan sensible en la zona, para lograr la cristalización de la paz entre israelíes y palestinos, este factor debe permitir la generación de un intercambio en las pretensiones entre las partes. El modelo de acuerdo de paz a largo plazo/interino considera fiable que para la solución del conflicto se renueve el diálogo sobre temas que anteriormente se han propuesto y que como en el caso del Acuerdo Gaza-Jericó fueron firmados por las partes. De igual forma se debe dialogar sobre aquellos puntos propuestos y no tratados, pues en ellos se encuentran las bases creíbles y viables para ser aplicados a la situación actual del conflicto.

\section{La crítica de Edward Said}

Said no solo se mostró en desacuerdo con el acuerdo Gaza-Jericó sino que esbozó sendas críticas al mismo, aduciendo una supuesta pretensión 
de dominación de los Estados Unidos sobre toda la zona. Según Said, el gobierno de Bill Clinton pretendía ampliar su influencia en la zona a través del Estado de Israel. La actitud personalísima de Said respecto del acuerdo Gaza-Jericó contrastó con la colaboración del propio Arafat para conseguir que el acuerdo llevara a disminuir la violencia en la región.

En su libro sobre el acuerdo Gaza-Jericó, Edward Said esbozó una serie de afirmaciones que invitaban por lo menos a pensar en un complot entre los Estados Unidos, Israel y Arafat para hundir cualquier posibilidad de un futuro Estado palestino. Afirmó Said:

Lamento dudar, por todas estas razones, de la posibilidad que la posición de Arafat sea enmendada de manera beneficiosa para el pueblo palestino: la echó a perder el día 13 de septiembre al firmar un acuerdo que es responsabilidad y logro suyo desde todos los puntos de vista. Su presencia ahora no es provechosa para el pueblo palestino, sino que lo es forzosamente para Israel, Estados Unidos y Europa, así como para algunos intereses árabes. Dicha presencia es la garantía de la continuidad del acuerdo que consagra la dependencia y la sumisión palestinas, que son las que motivan el apoyo internacional del acuerdo. (Said, 1995).

Said fue uno de los críticos de Arafat, al tiempo que rechazaba los acuerdos firmados por este pues aducía la entrega de tierras que serían palestinas a favor de los israelíes y de la influencia estadounidense en la región. En mi opinión, Said erraba en su crítica, por cuanto no contempló en ella la posibilidad de que estos fueran un primer paso para la materialización de un plan de paz creíble en la zona.

Los sendos acuerdos firmados por el Estado de Israel con Egipto y Jordania, así como los firmados con la OLP, no significaban para Said pasos sólidos y realistas para la paz, sino una intención clara de parte de los israelíes de desplazar a los palestinos de lo que serían sus tierras en un futuro Estado palestino. Por el contrario, este modelo pretende tomar como base estructural de las negociaciones de paz parte de los acuerdos firmados y vigentes hoy entre las partes, los cuales pueden 
darse por definitivos e inviolables una vez que esto se acuerde entre israelíes y palestinos.

Los acuerdos firmados durante las últimas seis décadas de conflicto deben ser refrendados, de tal forma que dentro del modelo de negociaciones a largo plazo estos sean la base sobre la cual se inicien las negociaciones de paz. Defender los acuerdos vigentes entre ambas partes no difiere de este planteamiento de paz, en cuanto a la necesidad de traer a la mesa de diálogo aquellos puntos que se han propuesto a lo largo de las distintas negociaciones de paz y conferencias internacionales que han sido rechazadas por las partes. La solución del conflicto no pasa en su totalidad por nuevas inventivas, en cambio sí es necesario comprometer a las partes a analizar aquellos puntos fiables y creíbles que fueron rechazados por motivos políticos y personalistas.

Lo anterior es totalmente opuesto a la opinión de Said, quien veía en estos acuerdos una falsa premisa, específicamente sobre el de Gaza-Jericó afirmó que: «[...] una atenta mirada al acuerdo del 4 de mayo firmado en el Cairo es suficiente para desvelar su objetivo: incrementar la legitimidad del dominio israelí sobre los Territorios Ocupados». (Said, 1995).

La lejanía realista de Said sobre los hechos en la zona, contrastaba con su llamado a los palestinos a retomar la belleza de la idea de Palestina que se materializó en la I Intifada. El rechazo del realismo hizo que Said negara la idea de un Nuevo Orden Mundial, es decir, del cambio de situación que se presentaba a nivel global posterior al final de la Guerra Fría y la caída del comunismo. Por el contrario, Said invitaba a defender el nacionalismo y la liberación. Su pensamiento no contribuyó al consenso ni al fin del conflicto, pues la paz, para ser conseguida, debe estar estructurada sobre hechos y actos que tengan como base la realidad de la población, de la seguridad, de la política y del ámbito internacional, pues ningún país está aislado de efectos globales.

El blanco de las duras críticas de Said dentro del proceso de paz fue la AP. No lo fue en menor medida el Estado de Israel, los Estados Unidos y Europa; sin embargo, en lo que tenía que ver con el gobierno de los territorios palestinos Said fue implacable en sus críticas. Fue en contraposición de la AP, criticó duramente todo acuerdo firmado por 
Arafat pues lo culpó de entregar tierras palestinas a los israelíes con el mero fin de ser reconocido a nivel internacional.

Consideremos la política de información de la Autoridad Nacional Palestina (ANP): aún no ha contado a su propio pueblo la entera verdad de la situación presente. $\mathrm{Si}$, por supuesto, todo palestino quiere un Estado independiente; pero ¿qué tipo de Estado? No se dice nada. ¿Va a haber resistencia a la ocupación o no? Ni una palabra. ¿Habrá asambleas consultivas? Ni una palabra. ¿Cuál es la política económica de la nueva entidad? (Aparte del estúpido lema de Singapur). Nadie parece saberlo [...] El acuerdo de Oslo sanciona efectivamente un protectorado israelí en Gaza y Jericó con la cacareada y encrestada policía palestina sirviendo de brazo ejecutor israelí. Tras esto, la OLP tiene poco que decir y ofrecer. (Said, 1995).

La fuerte crítica de Edward Said al acuerdo Gaza-Jericó dejó poco espacio en sus ideas para el acompañamiento de una negociación de paz, siendo también blanco de sus críticas el Acuerdo de Oslo, el que vio como la entrega de los territorios palestinos a manos de los israelíes. Sin embargo, al tiempo que Said criticaba a la ANP, a los israelíes y a los negociadores, alababa el «coraje» de los gazies para no sucumbir -según él- a la entrega de su territorio a manos de los israelíes.

Mi desacuerdo con Said radica en su postura opuesta a la solución coherente del conflicto y la crítica enconada hacia quienes hicieron frente a las negociaciones de paz, que además fueron reconocidas como exitosas a nivel internacional (no en vano, pocos dudan de los avances positivos conseguidos en 1993 con los acuerdos de Oslo, los cuales fueron un punto de referencia en la búsqueda de la paz entre israelíes y palestinos). Ensimismado en su ácida crítica, se opuso siempre a un acuerdo de paz entre las partes; su permanente idea de conspiración pudo más que su sabiduría. 


\section{Compatibilidad con las fronteras anteriores a 1967}

El acuerdo que intercambia seguridad en espacio aéreo y aguas marítimas contempla el desmantelamiento de los asentamientos que se acuerden dentro de las negociaciones de paz, al tiempo que la aceptación del acuerdo que conceda al Estado de Israel el control de la seguridad. En este orden de ideas, el muro de separación hace parte de las negociaciones, por lo que este -en el mejor de los casos- deberá desaparecer o ser reducido. El desmantelamiento de los asentamientos que sean acordados, contempla la modificación de las fronteras, es decir, la real demarcación de unas fronteras creíbles y seguras, que no necesariamente serán las anteriores a 1967 pues la situación, como se ha afirmado en ocasiones anteriores, no es la misma de entonces.

La razón que hace complementaria la situación de los asentamientos con las fronteras anteriores a 1967 consiste en el movimiento de fronteras construidas a partir de la guerra de los Seis Días, traducida en el levantamiento de asentamientos en los territorios adquiridos por el Estado de Israel durante dicha guerra. Por lo tanto, al hacer referencia a los asentamientos, me refiero a las fronteras anteriores y posteriores a 1967, de ahí que en este modelo ambos temas sean complementarios uno del otro.

Si se comparan el mapa de la partición del territorio diseñado por la ONU en 1947, el mapa posterior a la guerra de los Seis Días y el mapa actual del Estado de Israel se encontrará como los asentamientos son la piedra angular para la definición de unas fronteras definitivas. Lo que significa que esas fronteras definitivas dependen del desmantelamiento de los asentamientos a los que haya lugar en razón de la fundación de un futuro Estado Palestino y de la seguridad del Estado de Israel.

Los asentamientos empezaron a crecer de forma acelerada a partir de la Guerra de los Seis Días y hasta hoy, como forma del Estado de Israel de garantizar su propia seguridad, ya que la ANP no tenía capacidad de garantizarla en sus propias fronteras. Los asentamientos no son justificables bajo esta premisa, pues los mismos ciudadanos que los habitan regularmente sufren ataques violentos, por lo que no 
es una forma de protección y sí más bien de exposición de Israel de sus propios ciudadanos a condiciones de inseguridad, sin perjuicio de la presencia de militares israelíes que presten seguridad a los mismos.

La cuestión de las fronteras y el modelo de Estado fue, desde el principio, la piedra angular de la resolución del conflicto, así quedó demostrado en las discusiones en Naciones Unidas en 1947, cuando se buscaba afanosamente la calma en la zona, y ante el inminente final del mandato británico en Palestina.

Desde febrero de 1947, como indica A. Chouraqui, el centro de gravedad del problema palestino se desplazó de Londres a Naciones Unidas. Se entablan entonces negociaciones entre los Cinco Grandes y el Secretario General de U.N. que llevaban a la convocatoria de una sesión especial de la Asamblea General que se reunió entre abril y mayo de 1947, y que designó una comisión de once miembros para estudiar el problema de Palestina y hacer recomendaciones sobre la solución del mismo. (Martínez, 2002).

En la comisión se debatió desde la creación de dos Estados independientes con Jerusalén bajo mandato internacional, hasta la posibilidad de un Estado binacional con un sistema federal; el primero votado por la mayoría de la Comisión y el segundo por minoría. En todo caso, las razones que entonces fueron un escollo para la delimitación de fronteras, lo siguen siendo hoy entre los mismos actores del conflicto. Si nos retrotraemos a la época y la situación internacional que en ese momento se vivía, era apenas posible pretender que ambos aceptaran la decisión definitiva de Naciones Unidas.

Los hechos han probado que la simple toma de la decisión no fue acompañada de un compromiso creíble, por parte de las partes, de respetar la misma. En consecuencia «la Comisión concluyó por rechazar el plan de creación de un Estado federal y aprobó el otro plan de instauración de dos Estados independientes» (Martínez, 2002). Que los palestinos desaprovecharon su oportunidad o no en aquel momento ha sido el histórico debate que ha motivado innumerables discusiones emotivas que de nada han servido a la resolución del conflicto. 
Con la partición de la tierra se buscó poner fin a los hechos de violencia ya existentes en la zona. Sin embargo, no es a partir de la partición que éstos hechos se originan, y tampoco a partir de 1967, solo que antes no estaban en el centro de la política internacional, pues entonces la situación global era más compleja que ahora. «Desde 1936, como señala Derriennic, el problema árabe-judío en Palestina aparece cada vez más como el conflicto más grave que se plantea en la región, que no será esencialmente transformado por la guerra. En 1939 los factores que hacen este conflicto inevitable se encuentran ya activos». (Martínez, 2002).

Siendo considerado el conflicto árabe-judío como inevitable, entonces la reacción de la política global fue nula, de hecho el cese del mandato británico fue más traumático que una vía de resolución. Sin embargo, hoy el conflicto israelí-palestino es el único resquicio que existe de aquella época, superando incluso el periodo de la Guerra Fría. Además la resolución, en cuanto a las fronteras de uno y otro Estado, sigue siendo negativa, en parte porque los Estados Unidos y la AP insisten en regresar a las fronteras de 1967, sin tener en cuenta que la situación global ha cambiado, de tal forma que estas serían imposibles de materializarse, de acuerdo a la retórica de las partes.

En la actualidad, la situación de los asentamientos, como parte complementaria a la solución de las fronteras, obedece a cuestiones distintas de cuando Naciones Unidas partió la tierra en 1947, por ejemplo, hay condiciones de seguridad a las que se debe responder desde la base de la realidad, ya no solo de la zona, sino de la región. De igual forma, el diseño de unas nuevas fronteras también debe responder a las necesidades de la población palestina más urgida de ser ubicada en un territorio dentro de un futuro Estado palestino.

«La cuestión Palestina», como era denominada por Naciones Unidas, dejó de ser una cuestión entre palestinos y judíos para ser una cuestión regional, especialmente, después de la partición de la tierra y la declaración de un Estado de Israel, dada la participación de Egipto, Irak, Transjordania (Jordania) -que tenía pretensiones propias en cuanto a la tierra, específicamente en lo referente a Jerusalén, Siria, Líbano, e incluso en las guerras que se subsiguieron a la declaración del Estado de Israel. 
Una de las ofensivas estratégicas de los ejércitos árabes en 1948 se basó en cortar toda posibilidad de comunicación terrestre entre Jerusalén y la costa, lo que incluía los poblados judíos; así, una Jerusalén que entonces era compartida entre árabes y judíos pasó a ser desde entonces el bastión estratégico por el que las dos partes luchaban. Tanto árabes como judíos vieron entonces y ven hoy la importancia estratégica que conserva la salida al mar y la conexión de este con el centro de Israel, lo que antes se consideró una vía estratégica en la guerra de 1948, hoy se sigue considerando igual por las dos partes del conflicto. Si bien la forma de hacer la guerra ha cambiado, el mundo se enfrenta a nuevas tecnologías que han permitido que los métodos de guerra hayan evolucionado. La importancia estratégica de conectar o desconectar a Jerusalén con la costa sigue intacta.

Actualmente, el desafío para conseguir la resolución del conflicto consiste en transformar esas fronteras desmantelando asentamientos e intercambiando pretensiones por otros espacios estratégicos distintos, como lo propone nuestro modelo de negociaciones a largo plazo, pero que al mismo tiempo otorguen seguridad tanto a palestinos como a israelíes. Las partes deben ser emplazadas no a asfixiar una a la otra, no a resolver el conflicto con un victorioso y un derrotado, pues la resolución compromete a las partes a la edificación de una paz real, duradera y eficaz para la situación global.

Después de las guerras que siguieron a la partición de la tierra y la declaración del Estado de Israel, tuvo lugar la más grande transformación de fronteras entre ambos actores del conflicto, la Guerra de los Seis Días, lo ocurrido entonces fue y continúa siendo el centro del debate dentro de la resolución del conflicto. Parece no creíble que aún hoy la AP hable de la intención del Estado de Israel de llevar a cabo el entonces denominado Plan Allon ${ }^{3}$ que de hecho nunca fue aprobado por el parlamento israelí.

3 Denominado también Plan de Fronteras Defendibles, en su visión, compartida luego por los sucesivos primeros ministros de Israel, el concepto de fronteras defendibles significa que Israel tiene el derecho y la responsabilidad de establecer fronteras que satisfagan necesidades de seguridad básicas para sus ciudadanos, como lo opuesto a aceptar unas fronteras geográficas que inviten al ataque. 
Tras la Guerra de los Seis Días, el conflicto volvió a estar en el centro de la discusión global, y he de decir que nuevamente la comunidad internacional fracasó, pues árabes e israelíes se volvieron a enfrentar en la guerra del Yom Kipur en 1973. El mapa de 1947 no tiene nada que ver con el resultante de la guerra de 1967, que ha sido tal vez la modificación más profunda de fronteras desde la partición de la tierra.

Tras la guerra, los israelíes tomaron el control del Sinaí y Gaza, de Cisjordania (Judea y Samaria), entonces perteneciente a Jordania, además la totalidad de Jerusalén. Como consecuencia, Naciones Unidas aprobó la resolución $242^{4}$ de 1967 emplazando a los países de la zona a un compromiso por la paz duradera, sin embargo, a pesar de las sendas resoluciones, la cuestión sobre el terreno siempre ha sido distinta y más parece que Naciones Unidas y el Consejo de Seguridad han estado permanentemente de espaldas a la realidad. La prueba de ello es la resolución 2334 de 2016 , que prácticamente da a entender que incluso los barrios judíos están "ocupados" por los propios judíos.

Pese a la situación, la negativa al diálogo a la que emplazó la Cumbre Árabe en 1967 de «no negociar con Israel, no reconocer a Israel, no firmar la paz con Israel» (Martínez, 2002: 157), fue una política que solo perjudicaba a los propios palestinos de cara a los países árabes y a los israelíes hacia el exterior. Hubo que esperar hasta después de la guerra del Yom Kipur para que el mapa de 1967 se transformara luego de que de la firma de armisticios de 1949 con Egipto y Jordania se pasara la firma de tratados de paz.

Si bien el movimiento de fronteras de entonces no correspondió en su totalidad a la creación de asentamientos, hoy la resolución del

4 Retiro de las fuerzas armadas israelíes de territorios que ocuparon durante el reciente conflicto; Terminación de todas las situaciones de beligerancia o alegaciones de su existencia, y respeto y reconocimiento de la soberanía, integridad territorial e independencia política de todos los Estados de la zona y su derecho a vivir en paz dentro de fronteras seguras y reconocidas y libres de amenazas o actos de fuerza. Afirma además la necesidad de: a) Garantizar la libertad de navegación por las vías internacionales de navegación de la zona; b) Lograr una solución justa del problema de los refugiados; c) Garantizar la inviolabilidad territorial e independencia política de todos los Estados de la zona, adoptando medidas que incluyan la creación de zonas desmilitarizadas. 
problema de las fronteras sí necesita del reconocimiento de los asentamientos en este punto. La situación de entonces correspondió a la respuesta del Estado de Israel a las confrontaciones bélicas a gran escala con países árabes que incursionaban en la guerra mayormente por la tierra; de ahí que los israelíes adujeran la necesidad del dominio de las vías terrestres. Sin embargo hoy la situación no es la misma y para su seguridad necesita también el espacio aéreo y las aguas marítimas, y en este sentido nos reafirmamos en la necesidad del intercambio de tierra por espacio aéreo y aguas marítimas entre israelíes y palestinos.

La AP debe fijar una posición creíble para regresar a las negociaciones, una propuesta que no lleve incluida otra paralela (reconocimiento en Naciones Unidas), al tiempo que el gobierno del Estado de Israel debe sopesar, en primer lugar, la congelación de los asentamientos y la supresión de algunos ya existentes que deberán ser acordados por un acuerdo entre las partes.

El mapa actual del Estado de Israel nos muestra unas nuevas fronteras, es un mapa diferente. Aunque también difiero de este último, al señalar Jerusalén como un territorio ocupado, si bien su situación, aunque resuelta de forma unilateral por el Estado de Israel aún está pendiente en la resolución del conflicto, por lo cual nuestra investigación la ha designado como uno de los puntos estructurales profundos pendientes de resolver.

Tampoco Gaza es un territorio ocupado, pues la desconexión llevada a cabo en 2005 puso fin a la controversia en cuanto a esa parte de la zona, con los resultados que hoy conocemos, que no han sido los mejores ni para israelíes ni para palestinos. Hoy la ANP tiene el desafío de conseguir la desmovilización de Hamas, que gobierna ese territorio. Todo acto violento tendente a agravar la situación en Gaza y de estos hacia los ciudadanos israelíes solo dará razones al gobierno israelí para continuar negándose a que Hamas participe de las negociaciones.

Pareciera que el conflicto israelí-palestino se hubiera enfrascado dentro de su misma naturaleza. En este sentido, el modelo requiere que algunas propuestas que fueron expuestas en el pasado sean traídas nuevamente a la mesa de negociaciones, pues se entiende que el conflicto (antes y ahora) está basado sobre las mismas estructuras que han sido defendidas por sendos gobernantes estadounidenses: en primer lugar, 
el reconocimiento del derecho a la existencia del Estado de Israel; en segundo lugar, la negociación de fronteras permanentes, y por último, el derecho de los palestinos a una patria.

Figura 5. Mapa 1 de la partición de la ONU

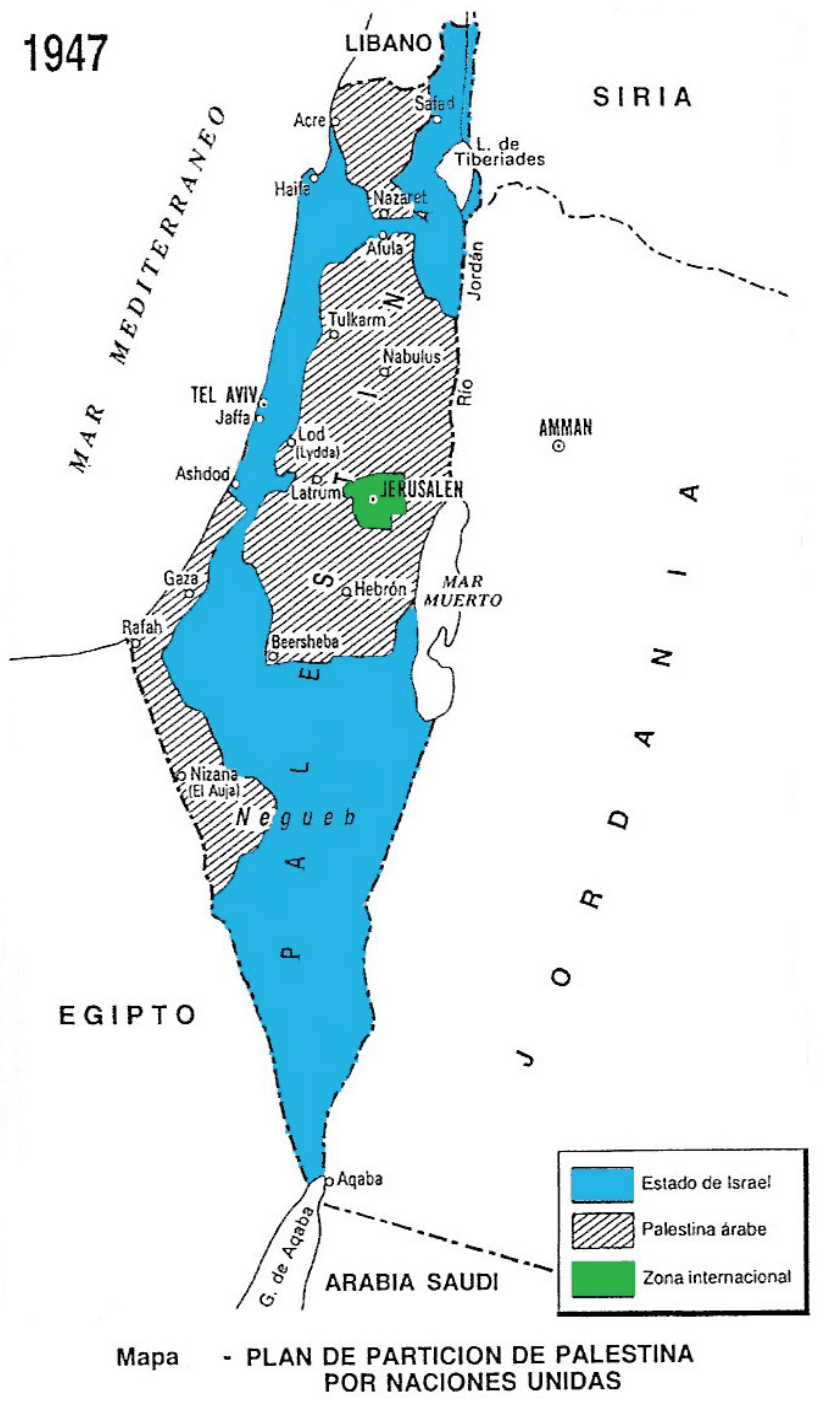

Fuente: recuperado de: https://elproyectomatriz.wordpress.com/2009/02/01/red-judia-antisionista-internacional/\#jp-carousel-7728 wordpress.com (2009). 
Hoy, es necesario volver sobre estos tres principios, que han sido «acomodados» por las partes a sus propios intereses, emergiendo de ellos indistintamente nuevos escollos. La realidad es que este último mapa debe ser transformado solo mediante el acuerdo de las partes, y no sin antes resolver sus problemas internos, como el caso palestino y la presencia de Hamas, quien se niega a reconocer la existencia del Estado de Israel. Al mismo tiempo, el gobierno israelí debe hacer su parte, que consiste en transformar este último mapa, para lo cual necesitará voluntad política, como la que demostró Ariel Sharon en 2005 con la desconexión de Gaza.

En la situación actual de las negociaciones de paz, y con respecto a este último aspecto, surge una interrogante para este modelo: ¿cuántos y cuáles asentamientos deben ser susceptibles de ser desmantelados? Esta propuesta de paz consistente en el diálogo cara a cara o directo, en cuyo caso opta porque los temas más sensibles de resolver sean absolutamente consensuados entre las partes, sin perjuicio de que los observadores de la ONU puedan dar sus opiniones respecto al tema.

La autodeterminación de los pueblos conlleva intrínseca la delimitación de las fronteras del mismo. En este sentido, no se puede incurrir en el error que hasta hoy ha cometido -entre otros- el gobierno actual de los Estados Unidos, al intentar resolver el conflicto tomando como base las fronteras anteriores a 1967, desconociendo la realidad de lo que hoy ocurre en la zona. En mi opinión, este es un factor negativo que aleja la solución del conflicto y congela las negaciones al punto de que, mientras en la zona se van materializando cambios -no necesariamente con resultados positivos-, las negociaciones tendentes a la solución del conflicto israelí-palestino no hace más que acentuarse.

\section{Solución de fronteras y situación actual}

La crítica que plantea el modelo a largo plazo interino, con respecto a la propuesta del actual gobierno de los Estados Unidos de tomar como base las fronteras anteriores a 1967, corresponde a que no se están teniendo en cuenta los cambios que a partir de 2011 se llevaron a cabo en la región. La participación de Egipto como mediador dentro 
del conflicto ha cambiado, de hecho hoy es clara la amenaza de que el acuerdo de paz de 1979 entre Egipto e Israel sea susceptible de ser alterado; tal y como lo expresaron en su momento los islamistas que accedieron al poder, el acuerdo finalmente se salvó de ser alterado con la llegada al poder del mariscal Abdelfatah Al Sisi.

Figura 6. Mapa 2. Israel tras la Guerra de los Seis Días

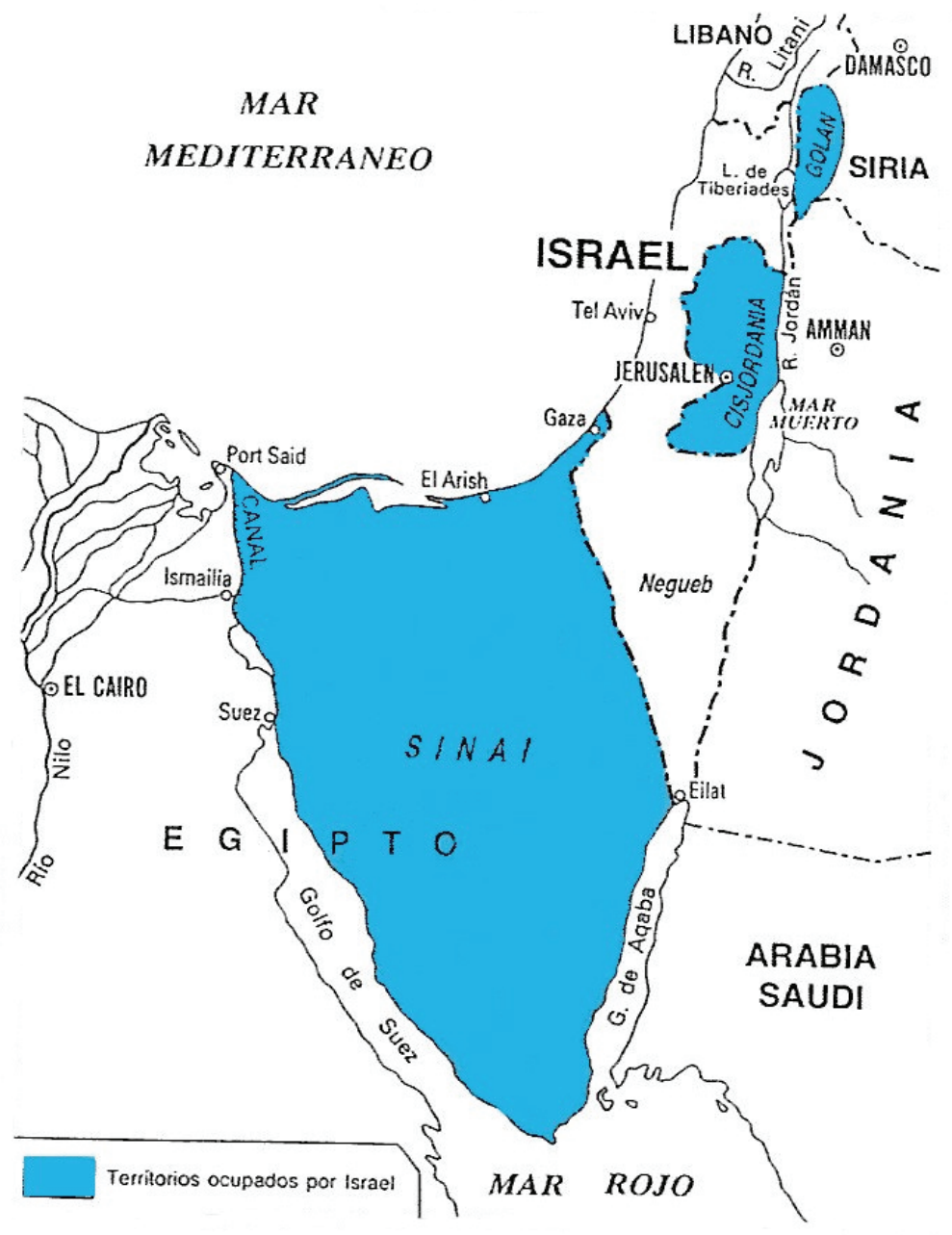

Mapa - ISRAEL TRAS LA GUERRA DE 1967

Fuente: recuperado de: https://elproyectomatriz.wordpress.com/2009/02/01/red-judia-antisionista-internacional/\#jp-carousel-7728 wordpress.com (2009).sionista-internacional/\#jpcarousel-7728 wordpress.com (2009). 
Siendo Egipto un país fundamental en la región, por lo que representa y por su influencia regional, el peligro de que este termine consolidando un régimen hostil a los Estados Unidos e Israel pone sobre la mesa la fragilidad de la consolidación de unas fronteras creíbles y seguras, ya no solo para los israelíes sino para los propios palestinos, pues no hay que olvidar que en los territorios palestinos no existe una unidad socio-política. La división entre la ANP (Fatah) y los islamistas de Hamas, apoyados por los Hermanos Musulmanes en Gaza, lejos está de permitir que los primeros puedan firmar un acuerdo definitivo sobre las fronteras anteriores a 1967.

Se ha propuesto la posibilidad de incorporar a Hamas en la mesa de negociaciones, pues esto equivaldría a implicarlos en la búsqueda de la solución al conflicto, a través de un alto al fuego que los comprometa a participar de las negociaciones, y que posteriormente debe traducirse en su desmovilización y entrega de las armas como contraprestación a su participación en un gobierno de unidad. Sin embargo, el plan de paz del actual gobierno de los Estados Unidos a partir de las fronteras anteriores a 1967 sería imposible de aplicar, toda vez que partir de estas significaría para Hamas el reconocimiento implícito de Israel como Estado.

Para definir unas fronteras reales y creíbles para los dos Estados dentro de esta volátil zona del mundo, las partes deben ser conscientes de que no se puede construir un Estado sobre lo que se desea sino sobre lo justo y real. Esto último nos indica que para llegar a la conformación de dos Estados ambas partes deben ceder en sus pretensiones; así, por ejemplo, el Estado de Israel posee tierra que puede llegar a ceder a favor de un futuro Estado palestino. No obstante persiste la pregunta por ¿qué están dispuestos a ceder los palestinos? En cuyo caso es válido resaltar que no se consigue la paz en detrimento de una de las partes, pero sí sobre el consenso de ambas.

Sobre este último interrogante recae la cesión de espacio aéreo y marítimo a favor de la seguridad de un Estado israelí y la protección de un futuro Estado Palestino, por lo que esto se aplica bajo la responsabilidad del Estado de Israel. El mundo no necesita otro Holocausto para justificar la existencia del Estado de Israel. Si bien la seguridad del Estado de Israel depende de sí mismo, no es necesario poner en riesgo 
un Estado ya constituido. El Estado de Israel existe, es real, tan real y válido como son las aspiraciones del pueblo palestino, por lo que la construcción de dos Estados debe ir necesariamente acompañada de realismo más que de emotividad.

Figura 7. Mapa 3. Israel en la última década del siglo XX

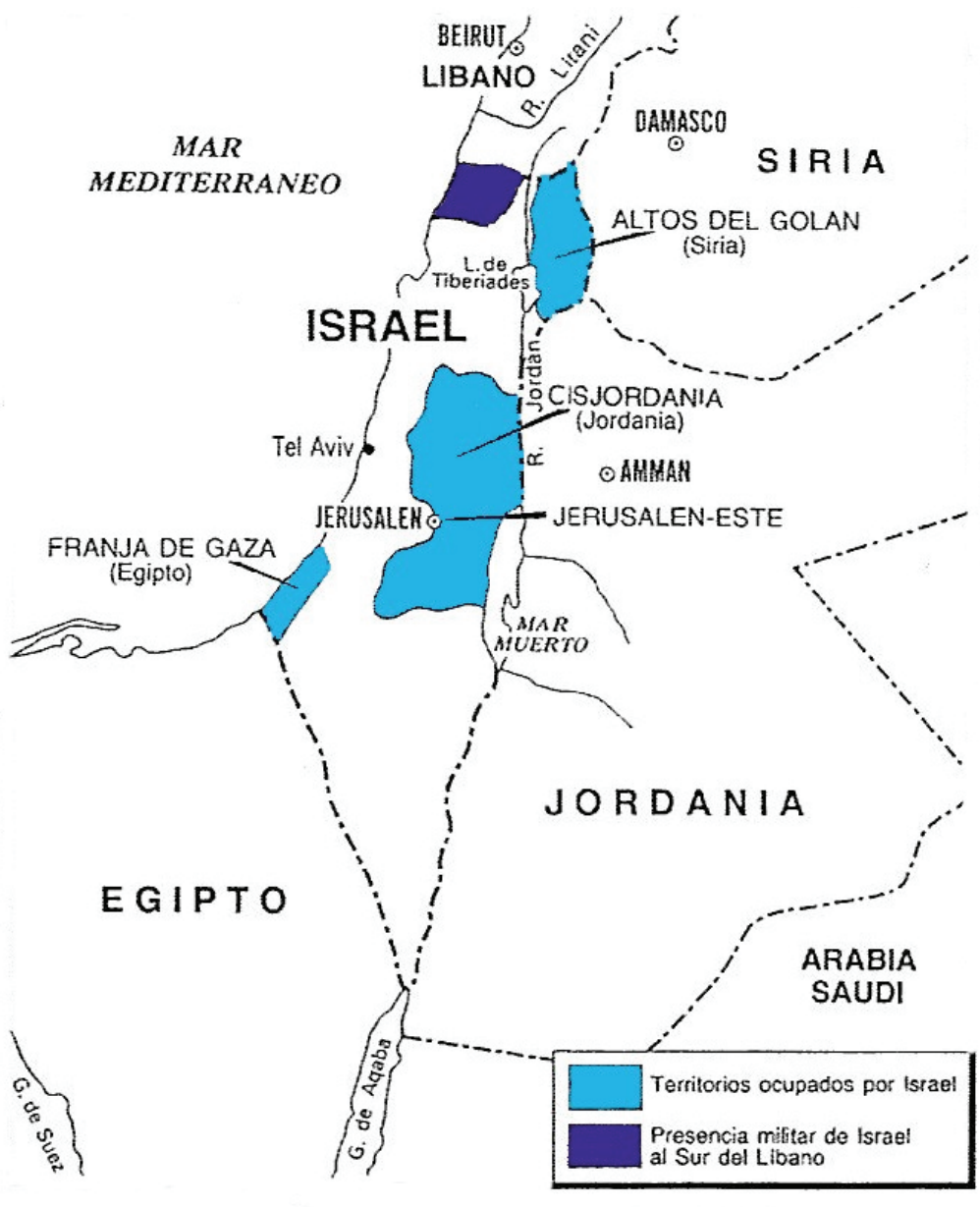

MAPA. ISRAEL ULTIMA DECADA S.XX

Fuente: recuperado de: https://elproyectomatriz.wordpress.com/2009/02/01/red-judia-antisionista-internacional/\#jp-carousel-7728 wordpress.com (2009). 
Sin embargo, conocemos lo ocurrido en Egipto después de las revueltas que llevaron a la dimisión de Hosni Mubarak y a la convocatoria de elecciones; el ascenso de los islamistas al poder y su posterior descenso; pero las noticias de Siria no son más que el baño de sangre causado a la población civil por el régimen de Asad y los diferentes grupos terroristas que poblaron ese país, el Daes (ISIS, por sus siglas en inglés) en primer lugar. Siendo Siria un vecino y enemigo declarado del Estado de Israel y lugar donde existen asentamientos palestinos ¿cuál será la reacción del régimen sirio cuando se vea más débil para conservar el poder? ¿Qué decisión tomará la población palestina que allí se asienta?

Los anteriores son solo interrogantes que surgen desde la perspectiva de la continuidad de Asad en el poder, pero como están pueden surgir otros si Asad es apartado del poder, sin obviar que el Golán permanece bajo control israelí y este conflicto no ha sido resuelto ¿qué sucederá si como en Egipto en su momento, los islamistas también acceden al poder en Siria o surge un régimen a fin a Iran? Todo lo ocurrido en 2011 y actualmente en la región debe tenerse en cuenta para la negociación de paz entre israelíes y palestinos, pues tampoco es descartable que un futuro Estado palestino pueda ser utilizado por islamistas como plataforma bélica no solo contra el Estado de Israel, sino contra su propio pueblo.

Otro de los factores que invitan a negociar tierra por espacio aéreo y marítimo es el programa nuclear iraní. Este programa no depende del presidente de turno en la República Islámica, en cambio sí es un objetivo continuo de los ayatolás, un país donde Estado y religión son una amalgama, los objetivos, en primer lugar, son colectivos y en segundo lugar, no se detienen con el cambio de poder. Por lo que, si Irán ejerce influencia en la región, en zonas específicas en las cuales tiene sus representantes, tales como Hezbollah en Líbano y Hamas en Gaza, ¿por qué no habría de estar el Estado de Israel preocupado por su propia existencia?

Es bien conocida por todos la negación continua de Irán acerca de la existencia del Estado de Israel y su constante amenaza con desaparecerlo, si esto no fuera creíble no estaríamos ante todas las sanciones que Europa y los Estados Unidos han aprobado contra Irán, 
entre ellas el embargo petrolero aprobado por la Unión Europea, que hoy han sido desmontadas gracias a la firma del Acuerdo de los 5+1 e Irán. Cuando el modelo a largo plazo aboga por emplazar a la permanencia de la cobertura en seguridad bajo responsabilidad israelí, lo hace a favor de la paz no solo para una de las partes sino para ambas.

La paz para ambas partes, bajo una negociación directa, con observadores de la ONU y garantes neutrales del proceso, corresponde a la consolidación de una paz duradera y creíble, por la que se puede arriesgar, apostar y la que se debe cultivar entre dos pueblos que están necesariamente abocados a tratarse y donde uno, el más fuerte puede ser partícipe de la construcción pacífica de su vecino.

\section{Alternativas desde el método Transced}

Los planteamientos anteriores animan a construir de forma más pormenorizada y utilizando la metodología Transcend. Dicho método tiene como estructura central tres puntos esenciales: diagnóstico, pronóstico y terapia.

\section{Diagnóstico}

Fueron y son muchos los escenarios mundiales en los que vivimos aquello que Samuel P. Huntington (1997) llamaba choque de civilizaciones. Según este autor, los conflictos presentes y los futuros no tendrán como fundamento una motivación ideológico-política sino cultural-identitaria, lo que por haber superado largamente el hecho binacional, merece una lectura más amplia y compleja. Se trata de un conflicto en sentido estricto entre dos posiciones fundamentales, entre dos modos de pensar, dos modelos de desarrollo y dos modos de concebir la vida y de creer en Dios, dos civilizaciones, dos ideas de paz: la árabe-musulmana y la judeo-cristiana-Occidental.

Se habla de desencuentro de modelos de desarrollo porque en la concepción de cada uno de ellos existen metas y utopías que orientan el destino, que son incompatibles entre sí, o que para realizarse una se tiene que eliminar a la otra. Así, como vimos en el primer capítulo, la 
concepción o autoconcepción que las sociedades tienen de sí mismas, determinan su concepto o idea de paz (Drago, 2006).

El concepto de Modelo de Desarrollo (MDD) fue acuñado por Aldo Capitini (1953), anticipado por Lanza del Vasto (1996: 60 y ss.) y desarrollado articuladamente por Johan Galtung (1984).

Las opciones posibles son las dos para cada alternativa; cuyas combinaciones dan lugar a cuatro parejas de opciones, es decir, a cuatro MDD. Galtung ha llamado los cuatro MDD, por medio de cuatro colores diferentes (empalmando el concepto de desarrollo con el sector de la defensa). Así, tenemos:

1. El modelo azul: el modelo con la opción capitalista y la carrera armamentista representados por los E.E.U.U. y por el oeste avanzado (GB, Francia, Alemania, Suecia e Israel).

2. El modelo rojo: el socialista-carrera armamentista, caracterizados por la autogestión o mejor dicho por el «control proletario», también por la bomba atómica (URSS y China).

3. El modelo amarillo: representado por el modelo capitalista-defensivo representado en parte por Suiza, el Japón y sobre todo por el Islam petrolero (que se basa en la férrea defensa de una fe personal y se coloca bajo guía de autoridades religiosas absolutas).

4. El modelo verde: el modelo socialista-defensivo que es precisamente el de la defensa civil no violenta de Gandhi, de Checoslovaquia (1968), de Irán (1979), de Filipinas (1986) y de la liberación de los pueblos del Este en 1989.

Con eso la teoría política de la no violencia es definible (estructuralmente) como la ideología política que se refiere al marco cultural de un pluralismo esencial, aquello de los cuatro modelos de desarrollo; y que propone el modelo de desarrollo verde (aquello autogestionario y con un desarrollo humanista). 


\section{El problema}

Luchar por el logro de objetivos incompatibles entre sí, materializados en la lucha por un territorio: por un lado, la convicción sionista de algunos judíos que desean recuperar el Israel definido en el Génesis bíblico como un territorio entre el Nilo y el Éufrates. Por otro lado, el extremismo de algunos palestinos/árabes/musulmanes que no quieren que exista Israel y desean que «sea borrado del mapa». Aunque es cierto que, en ambas partes, hay sectores que aceptan otro tipo de objetivos compatibles, tales como: el reconocimiento del Estado de Israel con fronteras seguras y con perspectivas razonables de paz , y el reconocimiento de un Estado Palestino en sentido pleno (y no un bantustán ${ }^{5}$ ) con derecho al retorno de los exiliados o expulsados. La capitalidad de Jerusalén está en el terreno de lo disputado, aunque sería solucionable. Pero los sectores extremistas parecen ser los que definen la agenda.

\section{Las partes}

Las partes están implicadas en un conflicto de desgaste por la soberanía de un territorio de cuya "co-soberanía» no se quiere hablar precisamente por el fuerte culturalismo de las demandas de cada una de ellas. A todas luces tenemos dos bloques (político-ideológico-religioso), conformado cada uno por dos elementos. En el bloque musulmán: Palestina y los países árabes; en el bloque Judío: Israel, Estados Unidos y los países OCSE.

- Palestina: es en este país es donde consideramos que hay fundamentalismo (en sentido estricto), planteamientos más radicales así como más moderados, más ligados al exterior y más autónomos,

5 Batustán es el término que designa cada uno de los veinte territorios que operaron como reservas tribales de habitantes no blancos en Sudáfrica y África del Sudoeste (actual Namibia), en el marco de las políticas segregacionistas impuestas durante la época del Apartheid. Tanto en la República Sudafricana como en el territorio aledaño de África del Sudoeste (por entonces, bajo su ocupación y administración), se establecieron diez reservas de esta clase, destinadas a alojar y concentrar en su interior poblaciones étnicamente homogéneas. 
más o menos corruptos. Aunque podríamos afirmar que, generalmente corruptos, lo fue la OLP, lo fue la AP y fue una de las razones por las que Hamas ganó las elecciones en Gaza.

- Bloque de países musulmanes: que se solidarizan con el pueblo palestino (en poco tiempo, algunos de estos países contarían con armas nucleares como en el caso de Irán).

- Israel: donde existe una mayoría judía aunque también los hay laicos, y pacifistas que no comparten de forma unívoca las pretensiones israelíes. Es importante no perder de vista a este segundo actor, fundamentalmente por la fuerte influencia de los medios occidentales, que con sus simplistas formulas duales (buenos- malos, terroristas-libertadores, islam-cristiano) prácticamente los han aislado. Es relevante señalarlos, con más razón si estos sectores son en realidad uno de los puntales para la búsqueda de salidas constructivas al conflicto.

- Estados Unidos y la UE: estos representarían aquí lo que llamaríamos un problema adicional inicial, que es la solidaridad con el pueblo israelí de parte de los Estados Unidos y con los palestinos de parte de la UE. Esto ha enquistado el conflicto, pues mientras unos confían en uno al mismo tiempo desconfían del otro. De ahí que veamos el rechazo de Israel a los llamamientos de la UE y en cambio sí atienda a los mismos, cuando estos provienen de los Estados Unidos. Sin embargo la AP, que anteriormente atendía los requerimientos estadounidenses, se ha venido plegando a los llamamientos de la UE.

Igualmente, ha habido propuestas razonables y viables para afrontar el conflicto desde instancias árabes, pero no estas han llegado a buen puerto debido, sobre todo, a la existencia de conflictos internos en cada una de las partes con apoyos cambiantes del exterior a lo largo del tiempo.

Otro elemento que vale la pena resaltar aquí es que sólo hay una potencia nuclear directamente involucrada en el conflicto (Israel), aunque los Estados Unidos lo estén de forma bien conocida. De ahí su capacidad de amenaza definitiva y de ahí también el deseo de sus vecinos y contrarios de contrarrestar o neutralizar algún día esa amenaza. 
Aquí, aunque la constitución del Estado de Israel sea democrática, es perceptible una fuerte presencia de los valores militaristas de la seguridad y del si vis pacem, para bellum (si quieres la paz, prepárate a la guerra) antes que los valores civiles de la paz y la resolución de conflictos. Por otro lado, Israel es uno de los países que más resoluciones de Naciones Unidas ha desobedecido, por encima y a mucha distancia de cualquier otro. El miedo a un segundo exterminio es una amenaza constante con la que convive el pueblo israelí, de ahí su afán de militarismo.

$\mathrm{Al}$ aplicar el triángulo $\mathrm{ABC}$ (modelo del referido «más allá de Galtung» con el doble triángulo) se obtiene lo siguiente (tabla 3):

Tabla 3. Doble triángulo de Israel

\begin{tabular}{|c|c|c|}
\hline Actitudes & Comportamiento & Contradicción \\
\hline $\begin{array}{l}\text { - Miedo a no tener } \\
\text { una tierra donde } \\
\text { protegerse y que se } \\
\text { repita la Shoah. } \\
\text { - Se siente víctima de } \\
\text { Palestina. } \\
\text { - Se presenta como la } \\
\text { única democracia } \\
\text { plural y respetuosa de } \\
\text { los DD.HH. que existe } \\
\text { en Medio Oriente. }\end{array}$ & $\begin{array}{l}\text { - Ocupación, } \\
\text { demolición de casas. } \\
\text { - Construcción del } \\
\text { muro (Ilegal según la } \\
\text { Haya). } \\
\text { - Acciones militares con } \\
\text { el fin de erradicar las } \\
\text { facciones palestinas } \\
\text { más radicales (la OLP, } \\
\text { Al-Fatah y Hamás). }\end{array}$ & $\begin{array}{l}\text { Derecho a un } \\
\text { territorio y respeto a } \\
\text { su estilo de vida. }\end{array}$ \\
\hline $\begin{array}{l}\text { - Necesidad de } \\
\text { convencer al otro } \\
\text { bando de que «el } \\
\text { pueblo judío no puede } \\
\text { destruirse». } \\
\text { - Orgullo por el éxito } \\
\text { económico y cultural } \\
\text { que ha alcanzado. } \\
\text { - Seguridad en } \\
\text { suejército. } \\
\text { - Misión mesiánica: } \\
\text { eliminación } \\
\text { deterroristas. } \\
\text { - "Somos un Estado } \\
\text { democrático". }\end{array}$ & $\begin{array}{l}\text { - Ataques a la población } \\
\text { civil. } \\
\text { - Extremas medidas de } \\
\text { seguridad. } \\
\text { - Desarrollo } \\
\text { armamentista. } \\
\text { bombanuclear. }\end{array}$ & \\
\hline
\end{tabular}

Fuente: elaboración propia. 
Tabla 4. Doble triángulo de Palestina

\begin{tabular}{|c|c|c|}
\hline Actitudes & Comportamiento & Contradicción \\
\hline - Miedo. & - Atentados suicidas. & $\begin{array}{l}\text { - Derecho a un } \\
\text { territorio y }\end{array}$ \\
\hline $\begin{array}{l}\text { - Vergüenza e } \\
\text { impotencia } \\
\end{array}$ & - Intifada. & $\begin{array}{l}\text { - Respeto a su estilo } \\
\text { de vida. }\end{array}$ \\
\hline - Frente a la imagen de & - Resistencia violenta. & \\
\hline $\begin{array}{l}\text { 5. violentistas que } \\
\text { se ha creado }\end{array}$ & $\begin{array}{l}\text { 6. - Apoyo a } \\
\text { grupos terroristas }\end{array}$ & \\
\hline en la opinion & pública & $\begin{array}{l}\text { (Hamás) no solo porque } \\
\text { dan }\end{array}$ \\
\hline mundial: son & todos & seguridad a la población, \\
\hline «terroristas». & & $\begin{array}{l}\text { sino porque han } \\
\text { establecido }\end{array}$ \\
\hline -Impotencia. & & $\begin{array}{l}\text { grandes redes de } \\
\text { asistencia }\end{array}$ \\
\hline -Desesperación. & & $\begin{array}{l}\text { social, salud, } \\
\text { educación,etc. }\end{array}$ \\
\hline -Odio. & & \\
\hline
\end{tabular}

Fuente: elaboración propia.

\section{Pronósticos}

Podemos destacar las siguientes ideas:

- Israel y los palestinos están inmersos en un conflicto de desgaste que lleva más de seis décadas. Continuarán en él mientras unos defiendan que el territorio está en disputa o que por el contrario está ocupado.

- Triunfo bélico de Israel (como ya se viene dando) sobre palestina, o, por el contrario, triunfo diplomático de los palestinos sobre Israel como ya lo vienen adelantando en la ONU.

- Triunfo de una de las civilizaciones, de una de las verdades que rige el mundo, la judía.

- Palestina continuará con su política de atentados y endurecerá las posibilidades de diálogo.

- Estados Unidos continuará con su política de cooperación militar a Israel provocando la ira del mundo musulmán. 
- Riesgo latente de que fundamentalistas musulmanes continúen con su política de atentados contra los Estados Unidos y sus aliados, etc.

\section{Terapia}

Figura 8. Terapia Israel-Palestina

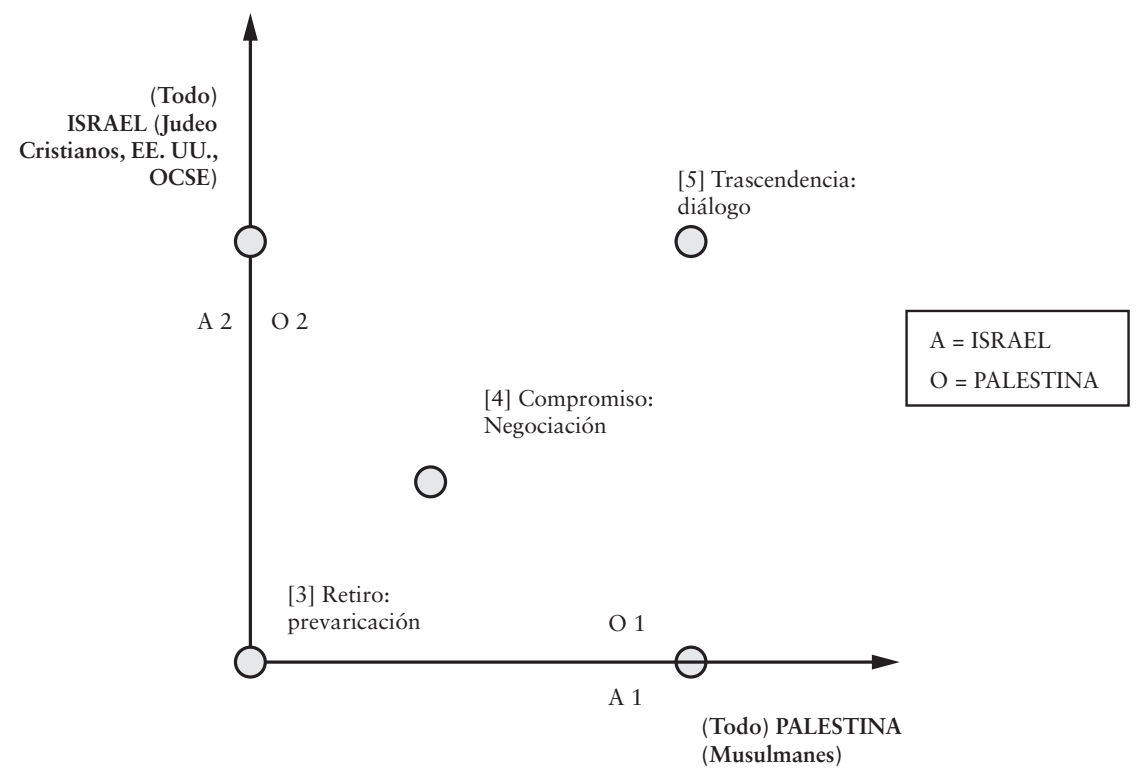

Fuente: elaboración propia.

Si nos concentramos en el conflicto territorial, gracias al ejemplo precedente, podemos tener ya un esbozo de las salidas que este conflicto puede tener bajo el esquema: «Dos naciones, un territorio».

1. Unilateral I: un Estado, solo Israel «transferencia de Palestina».

2. Unilateral II: un Estado, solo Palestina, los israelíes fuera.

3. Trascendencia negativa: un tercero domina (Otomanos, Gran Bretaña, Naciones Unidas).

4. Compromiso bilateral, solución de dos Estados, Israel y Palestina. 
5. Trascendencia positiva: dos naciones entran simétricamente en un Estado:

- Como una federación modelo (Suiza).

- Como un Estado unitario.

Ciertamente, lo ideal sería llegar a una trascendencia positiva. Pero necesitamos ser realistas y aceptar que este es un objetivo imposible, que además ya fue propuesto por Hannah Arendt y a su vez rechazado. Johan Galtung (2004) aconseja intentar obtener lo más que se pueda, y en este caso lo que es realmente posible es el (4) compromiso bilateral, solución de dos Estados, Israel y Palestina.

Esta posibilidad definitivamente tendrá repercusiones en el plano del desencuentro cultural, que señalaremos a continuación:

(1) y (2) Un lado prevalece: ¿Quién gana? / ¿Quién pierde?

1. Prevalece Israel (judeo-cristiano-occidental): con su actual política de seguridad, el uso de la violencia y la amenaza de sus armas nucleares puede lograr ocupar la totalidad del territorio palestino y condenar a estos a vivir en campos de refugiados permanentes. La construcción e imposición de un muro que divida y confine a los palestinos. Este triunfo representará, al mismo tiempo, el de la civilización occidental (neoliberal, economicista, reduccionista, etc.) sobre algunas culturas y regiones que aún se resisten a aceptarlo. Asimismo el triunfo de un estilo de «democracia armada».

2. Prevalece Palestina (árabe-musulmán): con sus pocos recursos (intifadas, atentados, secuestros, etc.) solo puede contener la expansión total de lo que reclama como su territorio, y quizás conseguir una posición de presión sobre el pueblo israelí. Si con el apoyo de otros países árabes logra una presión tal (militar convencional o terrorista) como para obligar a retirarse del territorio que reclama como suyo. Esta posibilidad, quizá utópica, comportaría al mismo tiempo una gran derrota de los valores defendidos por el Occidente judeo-cristiano: democracia, derechos humanos, laicidad del Estado, derechos de las mujeres, etc. 
3. Ni uno ni otro, abandono/retirada: en este caso pueden presentarse varios escenarios: a) El pueblo palestino decide retirarse del conflicto y «resistir» preservando sus valores. b) Los palestinos que pueden escapar del país lo hacen pero con el objetivo de regresar algún día y vengarse. c) El pueblo israelí decide reducir las incursiones militares y las confrontaciones directas, pero continúa con la guerra cultural. d) Se deja todo en manos de la ONU quien a su vez es la defensora de los valores desarrollados en la cultura occidental. Esta posibilidad no estaría considerada en este caso dado el progreso de los acontecimientos y de los odios acumulados.

Un ejemplo clásico-histórico de «abandono/retirada» en el contexto de conflictos inter-Estados, como lo señala Johan Galtung, es el de los "protectorados». Algo así como «ni tu ni yo», un tercero (país, los «Cascos Azules», la OTAN) que vengan a poner orden ante una aparente situación de ausencia total de voluntad/visión para solucionar el conflicto. El punto nodal en la definición de esta «transferencia negativa» es que, en el fondo, el conflicto no se transforma, a lo más se pospone (lo cual en ocasiones no es en sí mismo negativo, sobre todo en condiciones de violencia eminente o escalonamiento ya en proceso).

4. Compromiso/negociación: sobre el terreno de los compromisos, que tiene evidentes limitaciones si se miran los resultados negativos, se ha estado intentando la salida al conflicto israelí-palestino desde años. Por ejemplo, al interior de este marco se han intentado negociar las fronteras, el reconocimiento mutuo como entidades estatales, el estatus de Jerusalén como capital compartida, el retorno de los refugiados y la restitución/compensación, etc.

5. Trascendencia (terapia): algunas consideraciones previas. Algo muy importante que recomienda Johan Galtung, en este caso específico, es seguir el siguiente principio: «Cualquier cosa que quieras para ti mismo, deberías deseárselo a la otra parte, si ella lo desea» (Galtung, 2004: 147). ¿Un Estado israelí? Entonces también uno para Palestina. ¿Una capital en Jerusalén? Entonces también para Palestina (en el Oeste para uno y en 
el Este para el otro). ¿Derecho al retorno de los judíos? Pues también para Palestina, y de igual forma, ¿seguridad para un futuro Estado palestino? Entonces también para Israel.

El método Transced tiene como base científica los estudios para la paz, por lo tanto aboga porque ninguna de las partes pierda o, en todo caso, porque ambas cedan. Como señala el profesor Jiménez Bautista,

La Investigación para la paz (Peace Research), intenté explicar estos mecanismos desde unos planteamientos diferentes de cómo se construyen esas relaciones, quizás de poder, [...] Nosotros apostamos por desmontar todos esos discursos desde el concepto de paz neutra, que nos ayude a explicar todas las deslegitimaciones de la violencia cultural constitutiva de las desigualdades provocadas por las violencias estructurales y directas dentro de la sociedad en que cada ser humano vive. (Jiménez, 2011, p. 68).

Frente a este tipo de conflictos tenemos que tener siempre presente que, al igual que Vietnam y Cuba (con la crisis de los misiles), estos son lugares (conejillos de indias) que en ocasiones pueden ser usados por grandes potencias para ejercer bloques o medir sus fuerzas con otras regiones del mundo. Por ende, se necesitaría fortalecer las instancias supraestatales que pudieran afrontar, con autoridad e imparcialidad, los conflictos entre sus miembros y entre los grupos de sus miembros. Como hemos señalado al inicio, Israel es uno de los el país que más resoluciones de Naciones Unidas ha desobedecido y lo justifica en su necesidad de seguridad. Esta instancia supraestatal debería ser, hoy en día, la Organización de las Naciones Unidas, cuya Carta, en el capítulo I, artículo 1.1, afirma que sus propósitos son los de:

Mantener la paz y la seguridad internacionales, y con tal fin: tomar medidas colectivas eficaces para prevenir y eliminar amenazas a la paz, y para suprimir actos de agresión u otros quebrantamientos de la paz; y lograr por medios pacíficos, y de conformidad con los principios de la justicia y del derecho internacional, el ajuste o 
arreglo de controversias o situaciones internacionales susceptibles de conducir a quebrantamientos de la paz.

Y en el 2.4, se lee lo siguiente: «Los Miembros de la Organización, en sus relaciones internacionales, se abstendrán de recurrir a la amenaza o al uso de la fuerza contra la integridad territorial o la independencia política de cualquier Estado, o en cualquier otra forma incompatible con los Propósitos de las Naciones Unidas».

A todo esto habría que adicionar algunas trascendencias globales:

- Necesitamos transcender la ONU. Seguramente sí, sobre todo si esta se fundamenta en una "formalidad» que puede ser sistemáticamente violada por los países que detentan el poder de veto en el Consejo de Seguridad (que son las cinco potencias nucleares) y, sobre todo, por los Estados Unidos, quien propende por una aplicación universalista de la norma, en ocasiones de forma velada.

- Trascender los conceptos «formales» de democracia. Como diría Amartya Sen, en su conocida tesis Las democracias no inician guerras, esta es una trascendencia a largo plazo, pero que tendría que comenzarse a construir hoy mismo desde la reconstrucción de los tejidos sociales básicos: individuo, familia y comunidad.

- Finalmente, trascender la formalidad universal de la llamada «globalización» no es suficiente (sobre todo si esta se da fundamentalmente en términos económicos). El hecho es que el mundo está dividido en clases sociales, y políticamente en conjuntos que se pueden denominar Occidente y Oriente. El primero concentra mayores cotas de poder y de clases altas que el segundo, aunque en el segundo se den también cotas de poder y clases altas que actúan como "caballo de Troya" de los intereses de las clases altas de los países centrales. Por parte de estos no parece que haya habido un interés real por reducir la brecha que separa a los ricos de los pobres y sí lo ha habido por supeditar lo más posible el destino de los países periféricos a la satisfacción de los propios intereses. 
Algunas trascendencias locales:

- A nivel regional: equilibrios de fuerzas a través de confederaciones con intercambios económicos entre naciones árabes, y con Israel (remarcando que se trata de la potencia económica y del mercado más fuertes en la región).

- A nivel bilateral: creación de federación multi-nacional y mecanismo para generar interdependencias económicas y políticas y, a mediano plazo, sociales. La co-habitación cooperativa (con igualdad, reciprocidad y simetría entre sus habitantes) como forma de sembrar la trascendencia pacífica para el futuro.

- La capital de Palestina en Jerusalén oriental.

- Una comunidad de Medio Oriente con Israel, Palestina, Egipto, Jordania, Líbano y Siria como miembros plenos, con regímenes de control de armas, agua y comercio basados en el consenso multilateral; y una Organización para la Seguridad y la Cooperación en el Medio Oriente con una base más amplia.

- La comunidad es apoyada por los Estados Unidos y la Unión Europea, el Consejo Nórdico y ASEAN financieramente y para la creación de profesionalismo en la construcción de instituciones.

- Egipto y Jordania ceden tierra adicional a Palestina.

- Las dos capitales vecinas se convierten en una confederación de ciudades, también hospedan a instituciones regionales mayores de las Naciones Unidas y ecuménicas.

- Israel y Palestina emprenden una cooperación económica conjunta y equitativa, educación para la paz conjunta, patrullaje fronterizo conjunto.

- Estacionamiento masivo de fuerzas y monitoreo de las Naciones Unidas.

- Tarde o temprano hay que poner en marcha el proceso de las Comisiones de la Verdad y la Reconciliación. 